Ph.D. Thesis

\title{
The role of the cerebellum in acute generalized convulsions
}

\section{Zoltán Tóth M.D.}

Supervisor: Prof. András Mihály M.D., Ph.D., D.Sc.

Department of Anatomy, Histology and Embryology

Faculty of Medicine

University of Szeged

Szeged 


\section{CONTENTS}

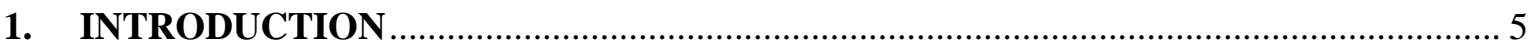

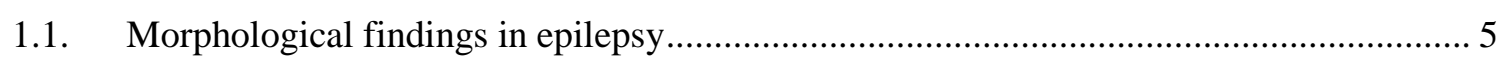

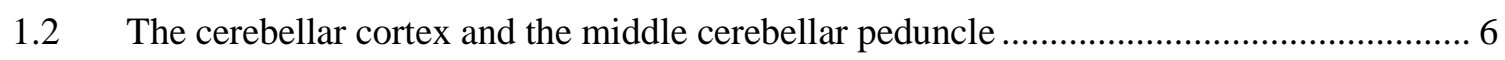

1.3 Glutamate transmission and glutamate receptors in the cerebellum .................................. 7

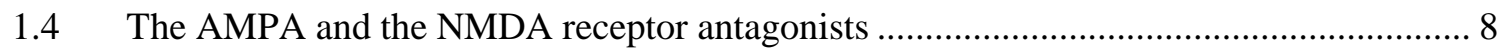

1.5 The 4-aminopyridine (4-AP) model of epilepsy ............................................................ 9

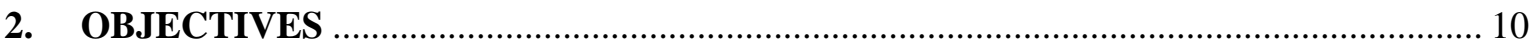

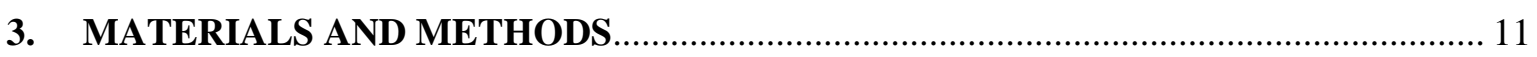

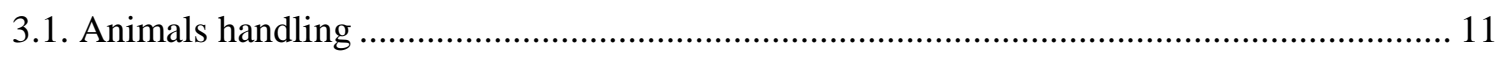

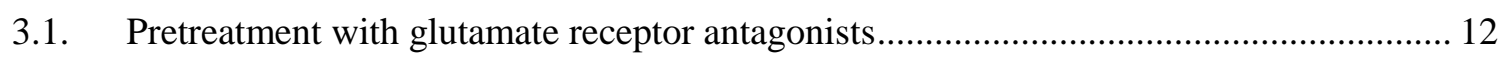

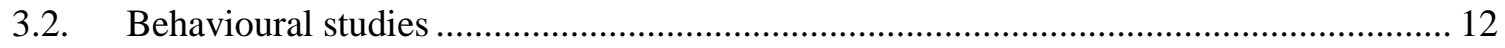

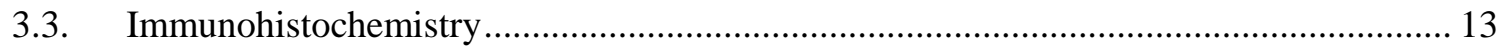

3.4. Morphometric analysis of the immunohistochemical data.............................................. 13

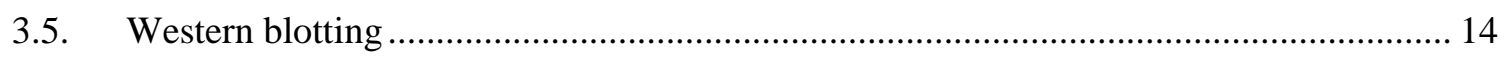

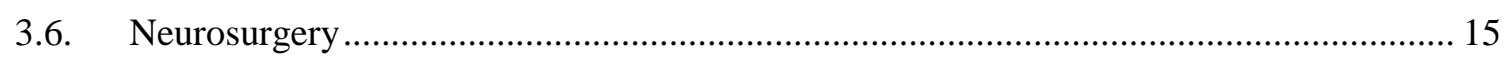

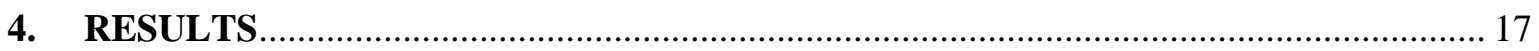

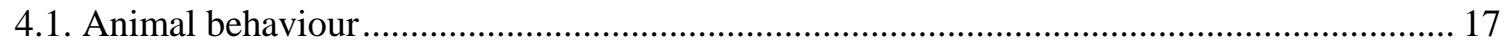

4.2 Number of c-fos immunoreactive cell nuclei in the cerebellar vermis following 4-AP

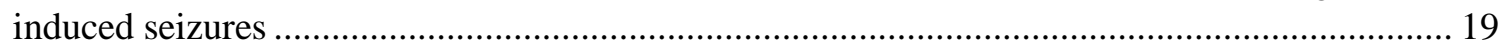

4.3 Number of c-fos immunoreactive cells in the cerebellar vermis following pretreatment

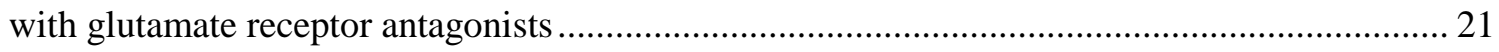

4.4 C-fos immunoreactivity and Western blotting after transection of the middle cerebellar peduncle

4.5 Histology and immunohistochemistry cerebellar cortex after the transection of the middle

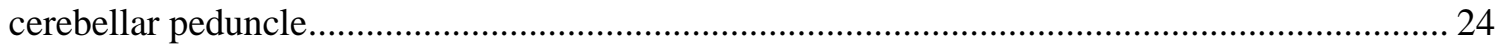

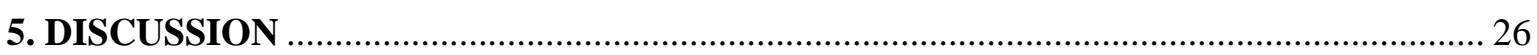

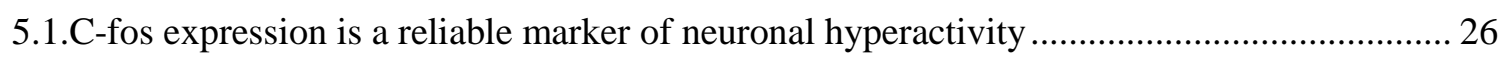

5.2 C-fos expression pattern of the cerebellar granule cells following 4-AP induced seizures

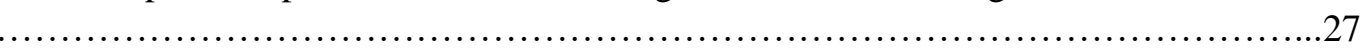

5.3 Effects of the glutamate receptor antagonists on the seizure symptoms and the c-fos expression in the cerebellar cortex.

5.4 The role of the mossy fibers in seizure induced c-fos expression of the cerebellar granule

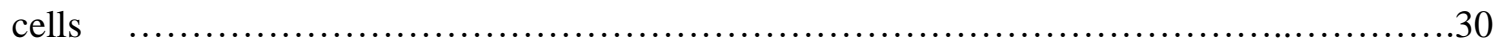

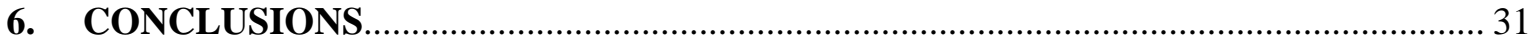

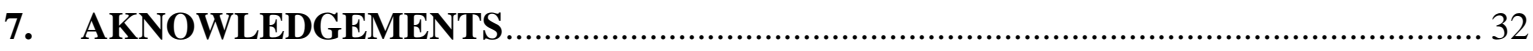

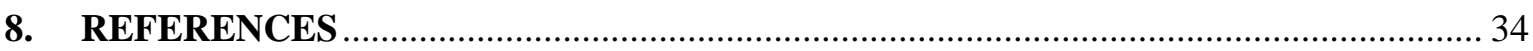




\section{LIST OF PUBLICATIONS RELATED TO THE THESIS}

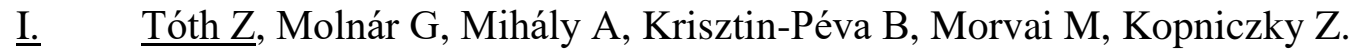
Immunohistochemistry of cerebellar seizures: mossy fiber afferents play an important role in seizure spread and initiation in the rat.

Acta Histochem. 2015 Jan;117(1):47-55. doi: 10.1016/j.acthis.2014.11.002. Epub 2014 Nov 22.

\section{IF: $\mathbf{1 , 3 4 7}$}

II. Tóth Z, Mihály A, Mátyás A, Krisztin-Péva B.

Non-competitive antagonists of NMDA and AMPA receptors decrease seizureinduced c-fos protein expression in the cerebellum and protect against seizure symptoms in adult rats.

Acta Histochem. 2018 Apr;120(3):236-241. doi: 10.1016/j.acthis.2018.02.004. Epub 2018 Feb 22.

\section{IF:1,719}




\section{ABBREVIATIONS}

AOI: $\quad$ area of interest;

AMPA: $\quad \alpha$-amino-3-hydroxy-5-methyl-4-isoxazolepropionic acid;

ANOVA: analysis of variance;

4-AP: $\quad$ 4-aminopyridine;

DAB: $\quad 3,3$ '-diaminobenzidine tetrahydrochloride;

EDTA: ethylenediaminetetraacetic acid;

fMRI: $\quad$ functional magnetic resonance imaging

GABA: $\quad \gamma$-amino butyric acid;

GFAP: $\quad$ glial fibrillary acidic protein;

GTCS: $\quad$ generalized tonic-clonic seizure;

IgG: $\quad$ immunoglobulin $\mathrm{G}$;

i.p: $\quad$ intraperitoneal;

IR: $\quad$ immunoreactive;

MCP: $\quad$ middle cerebellar peduncle;

MCPL: $\quad$ middle cerebellar peduncle lesion;

MRI: magnetic resonance imaging

mRNA: messenger ribonucleic acid;

NMDA: $\quad$ N-methyl-D-aspartic acid;

PAP: $\quad$ peroxidase-anti-peroxidase;

PBS: $\quad$ phosphate buffered saline;

PVDF: $\quad$ polyvinylidene fluoride;

RT-PCR: $\quad$ reverse transcription polymerase chain reaction;

SDS-PAGE: sodium dodecyl sulphate polyacrylamide gel electrophoresis;

SOC: $\quad$ sham-operated control. 


\section{INTRODUCTION}

\subsection{Morphological findings in epilepsy}

Many brain regions and their principal neurons are involved in acute seizures and chronic epilepsy. The most important regions are the pyramidal cells of the neocortex, the relay cells of the thalamus, the pyramidal cells of the entorhinal cortex, parahippocampal gyrus and the hippocampus (Pastor et al., 2014). Thalamocortical and limbic neuronal networks and,- the amygdaloid complex are also participating in generalized rodent epilepsies (Kostopoulos 2001). The repeated activation of these neuronal networks causes neuropathological alterations which resemble those observed in human epilepsy such as are the thinning and gliosis of the neocortex,- and the ongoing neurodegeneration in the hippocampus (M Thom, 2004). In some human epilepsies, the atrophy of the cerebellum is also detected (Spielmeyer, 1930., Dam, 1987., Botez et al., 1988). In these epilepsy cases, cerebellar atrophy is observed macroscopically, as the narrowing of the folia in the vermis, in the anterior and posterior lobes of the cerebellar hemispheres (Crooks et al., 2000). The histology of autopsy material reveals the shrinkage of the cerebellar cortex and the decrease of the number of Purkinje cells (Honavar and Meldrum, 2001). The neuropathological investigations proved that the Purkinje cells are sensitive to seizures: in chronic epilepsy the number of Purkinje cells is decreased significantly, and a reactive Bergmann gliosis was observed as well (R. Crooks et al., 2000). Cerebellar atrophy has been demonstrated following acute and chronic phenytoin administration in clinical epilepsy studies (Ney et al., 1994). MRI proved a correlation between the cerebellar atrophy atrophy and the duration of exposure to phenytoin (De Marco et al., 2003). Although seizures are rarely generated primarily in the cerebellum, several epileptic patients present cerebellar symptoms and cerebellar epileptic foci have been demonstrated, too (Boop et al., 2013). Despite its long recognition there have been very few studies regarding the anatomical distribution of cerebellar damage in epilepsy. The neocorticoponto-cerebellar connections often participate in these pathologies (Mohamed et al., 2011). Clinical studies using fMRI methods suggest the activation of neocortico-ponto-cerebellar circuits (Mohamed et al., 2011; Santarnecchi et al., 2012). Whether the presence of cerebellar atrophy modifies the seizure threshold remains to be clarified. The participation of the neuronal types of the cerebellar cortex in repeated seizures needs clarification too. 
1.2 The cerebellar cortex and the middle cerebellar peduncle

The cerebellum plays an important role in motor movement regulation and balance control. It is the largest part of the hindbrain, developes from the rhombencephalon in the posterior cranial fossa. The fourth ventricle midbrain, the pons, and the medulla oblongata are connected to it through the cerebellar peduncles . It has two hemispheres which are joined by the vermis. The hemispheres also are sub-divided in three lobes - anterior, posterior, and flocculonodular lobes. The cerebellum is composed of an inner white matter core that is covered by the gray matter of the cerebellar cortex. The white matter contains the deep cerebellar nuclei which play important role in the efferent connection of the cerebellum. The gray matter of the cortex divides into three layers: the outer molecular layer; the middle Purkinje-cell layer; and the internal granular layer. The molecular layer contains the dendrites of the Purkinje cells', the stellate cells, the basket cells and the arborization of the Bergmann glia cells (D’Angelo 2014). The Purkinje cell layer consists of the cell bodies of Purkinje cells and Bergmann glia cells. Apart from Bergmann glia, the cortex contains astrocytes, oligodendrocyte and microglia cells. The granular layer consists of the excitatory granule cells and the inhibitory Golgi cells. Climbing and mossy fibers provide the primary input to the cerebellar cortex. Mossy fibers terminate in the granular layer and use glutamate, while the climbing fibers terminating on the Purkinje cells use aspartate as their main excitatory neurotransmitter to provide excitatory signals to the cerebellar cortex (Ito 1984). The number of the granule cells is approximately four million in one $\mathrm{mm}^{3}$ cerebellar cortex tissue (Berends et al., 2004; Kim et al., 2013). The mossy fibers terminate on large synaptic complexes which are the cerebellar glomeruli (Jakab \& Hámori, 1988). Each glomerulus contacts at least 50 granule cell dendrites (Jakab and Hámori, 1988). Considering that a single granule cell has 4-5 dendrites and one mossy axon gives at least 20-25 axonal glomeruli, a single afferent mossy will stimulate several hundreds of granule cells (Kim et al., 2013). The cortico-ponto-cerebellar pathways in rodents terminate on the pontine (precerebellar) nuclei and the pontocerebellar axons form a huge crossed tract, which terminates mainly in the posterior cerebellar lobe (Brodal et al., 1979). The anterior 
lobe receives its afferents from the parietal, temporal, frontal and cingulate neocortex being predominantly ipsilateral, and probably less dominant in rodents (Ito 1984). The cerebellocerebral axons originating from the anterior lobe exert an inhibitory effect on cortical activity (Middleton and Strick, 1998). These cerebello-cerebral pathways terminate on thalamic nuclei and then thalamocortical afferents run to the neocortex (Palesi et al., 2015). The middle cerebellar peduncle (MCP) is the largest of the three paired cerebellar peduncles. The afferents of the MCP originate from the pontine nuclei, which receive strong input from the neocortex through the cortico-pontine pathway (Schmahmann and Sherman, 1998). The cortico-pontine tracts convey polysensory, associative, paralimbic and motor informations from the cerebral cortex to the pontine nuclei (Schmahmann and Sherman, 1998). The pontine nuclei send their axons to the cerebellar cortex: the pontocerebellar tract runs in the MCP and terminates as mossy fibers in wide areas of the cerebellar hemispheres and vermis (Azizi et al., 1985; Ruigrok, 2004).

1.3 Glutamate transmission and glutamate receptors in the cerebellum

The cerebellar granule cell is a glutamatergic neuron, which has NMDA and AMPA receptors on its dendritic tree (Geurts et al., 2003; Koutsuraki et al., 2013). The granule cell dendrites receive strong afferentation from the glutamatergic mossy fiber system (Hirano, 2013). The NMDA-mediated postsynaptic effects include $\mathrm{Ca}^{++}$influx and plasticity changes (Cull-Candy et al., 2001). The AMPA-mediated effects include desensitization (Xu-Friedman and Regehr, 2003) because of the large size of the mossy axon terminal. However, the participation and exact contribution of the AMPA- and NMDA receptors to the postsynaptic events in the cerebellar cortex is not known (Xu-Friedman and Regehr, 2003). The pontine nuclei provide the largest part of the mossy fiber afferents to the cerebellar cortex (Vejas, 1985). In epilepsy, the increased extracellular glutamate level can cause neuronal damage and degeneration (Meldrum et al., 1990). Increased level of extracellular glutamate causes long-lasting activation of glutamate receptors (Hansson and Rönnback, 1995; Hösli and Hösli, 1990), increases neuronal $\mathrm{Ca}^{2+}$ influx and precipitates intracellular cascades which finally lead to excitotoxic cell death (Glaum et al., 1990). Cerebellar Bergmann glia cells increased their GluR1 expression in cases of toxic glutamate concentrations, which raises the possibility of their protective role in glutamate 
neurotoxicity (Suárez et al., 1997). A similar role for cerebellar astrocytes can be hypothesized, on the basis of literature data (Pérez-Kapote et al., 2004). These features of the cerebellar glia point out to the importance of the transient glutamate accumulation in the extracellular space in conditions of neuronal hyperactivity. This glutamate spillover can be consequence of the structural organization of the cerebellar cortex: the large

glutamatergic glomerular synapses in the granular layer are surrounded by astrocytic „capsule” which inhibits the clearance of extracellular glutamate and probably does not have enough capacity for excessive glutamate uptake. Glutamate spillover may affect the mossy fiber synapses, causing synaptic swelling, long lasting synaptic excitation or longterm synaptic plasticity (Hirano et al., 2013). Glutamate released from the mossy synapse obviously stimulates a large number of cerebellar granule cells (Delvendahl and Hallermann, 2016). This endurance of the cerebellar glutamate transmission precipitated massive c-fos protein expression as proven by our previous experiments (Tóth et al., 2015).

1.4 The AMPA and the NMDA receptor antagonists

The ionotropic NMDA-type glutamate receptor antagonist MK-801, ((+)-5-methyl-10,11dihydro-5H-dibenzo[a,d]cycloheptan-5,10-imine maleate, dizocilpine) is a selective, noncompetitive antagonist, which has anticonvulsant and neuroprotective effects, too (Wong et al., 1986; Braitman and Sparenborg, 1989; Szakács et al., 2003). The low-affinity NMDA receptor blocker amantadine (1-aminoadamantane) have also anticonvulsant and neuroprotective roles (Kornhuber et al., 1994; Szakács et al., 2003). The GYKI-52466 (1(4-aminophenyl)-4-methyl-7,8-methylenedioxy-5H-2,3-benzodiazepine hydrochloride) is a selective, non-competitive antagonist of the AMPA-type glutamate receptors (Arai, 2001; Weiczner et al., 2008). Previous experiments from our laboratory proved that seizureinduced c-fos protein expression in the neocortex and hippocampus can be significantly inhibited by MK-801, amantadine (memantine) and GYKI-52466 pretreatment (Szakács et al., 2003; Weiczner et al., 2008). Closer investigation of the different receptor blockers revealed different action mechanisms in case of the NMDA- (Zádor et al., 2008) and AMPA receptor antagonists (Weiczner et al., 2008). The aim of present study was to measure the net changes in c-fos expression of cerebellar granule cells in the 4-AP acute seizure model following pretreatment with MK-801, amantadine and GYKI-52466, and 
compare their effectiveness on local neuronal activation (c-fos expression) and on the complex behavioural symptoms of the 4-AP convulsion.

1.5 The 4-aminopyridine (4-AP) model of epilepsy

In our experiments we have used 4-aminopyridine (4-AP) for seizure induction. Aminopyridines are $\mathrm{N}$-heterocyclic amines, which can block the voltage-dependent $\mathrm{K}^{+}$ channels. The prolonged action potential increases transmitter release in different CNS regions (Versteeg et al., 1995). The increased presynaptic activity caused by 4-AP increases synaptic vesicle exocytosis (Tokunaga et al., 1979). The drug crosses the bloodbrain barrier and will be rapidly elininated by the kidney (Lemeignan et al., 1984). The increased synaptic activity induces an intensive c-fos expression in many brain regions (Mihály et al., 1997, 2001, Kovács et al., 2003, Szakács et al, 2003, Kopniczky et al., 2005). The postsynaptic c-fos mRNA expression correlates well with the presynaptic release of excitatory neurotransmitters (Labiner et al., 1993). Our previous studies proved that c-fos protein is a reliable marker of neuronal hyperactivity in 4-AP induced acute seizures (Mihály et al., 2001, 2005; Szakács et al., 2003; Kopniczky et al., 2005). During the 4-AP seizure the increase of the number of c-fosIR cell nuclei displayed a characteristic pattern: maximum numbers of the c-fosIR cells were seen at 1 hour after 4-AP treatment in the neocortex, dentate gyrus and striatum (Kovács et al., 2003; Mihály et al., 2001; 2005). According to our RT-PCR measurements in the neocortex, the $c$-fos mRNA expression dynamics showed a similar pattern, i.e. maximum expression at $1 \mathrm{~h}$ (Mihály et al., 2005). Seizure-induced c-fos protein expression can be inhibited by NMDA- and AMPA receptor antagonists (Szakács et al., 2003; Weiczner et al., 2008), and dexamethasone pre-treatment (Fazekas et al., 2006). 


\section{OBJECTIVES}

I. The aim of our studies was to investigate and describe the timing and anatomical distribution of the activated granule cells in the cerebellum following 4-AP seizures, using c-fos immunohistochemistry and Western blotting.

II. The aim of our work was the development of a surgical method of the unilateral MCP lesion in laboratory rats.

III. We intended to clarify the role of the mossy fibers seizure-related cerebellar activation, through the unilateral lesion of the MCP by investigating the c-fos expression of the cerebellum.

IV. We wanted to investigate the role of glutamate receptors in cerebellar seizures by evaluating the changes in c-fos expression in the 4-AP seizure model following pretreatment with AMPA and NMDA receptor antagonists. 


\section{MATERIALS AND METHODS}

\subsection{Animals handling}

Adult male Wistar rats weighing 200-250 g were housed in a light- and a temperaturecontrolled room (lights on between 6:00 a.m. and 6:00 p.m.; $23^{\circ} \mathrm{C}$ ), and had free access to food and water. The animals were kept and handled during the experiments (including surgery) in accordance with the standards and prevailing laws and ethical considerations of the European Union (European Community Council Directive; 2010/63/EU). Written permission of the protocols of the experiments was obtained from the Ethical Committee for the Protection of Animals in Research of the University of Szeged, Szeged, Hungary. In the first group of animals $(n=9)$ seizures were induced with a single intraperitoneal (i.p.) injection of 4-aminopyridine (4-AP; Sigma-Aldrich, St. Louis, MO, USA) dissolved in physiological saline $(5 \mathrm{mg} / \mathrm{kg} 4-\mathrm{AP}$ in $1.0 \mathrm{mg} / \mathrm{ml}$ concentration). Control animals $(\mathrm{n}=9)$ received the same volume of physiological saline, i.p. Rats treated with 4-AP displayed generalized tonic-clonic motor convulsions (Mihály et al., 1990). At the end of the convulsions, i.e. 1.5, 2 and $3 \mathrm{~h}$ following the i.p. 4-AP injection, the rats were deeply anesthetized with diethyl-ether (Fluka). The chest was opened, the ascending aorta was cannulated and the animal was perfused with cold fixative. The fixative contained $4 \%$ paraformaldehyde in $0.1 \mathrm{M}$ phosphate buffer, $\mathrm{pH}$ 7.4. Following transcardiac perfusion, the brains were dissected and postfixed in the same fixative for $8-12 \mathrm{~h}$ at $4^{\circ} \mathrm{C}$. The vermis and the hemispheres were separated and soaked in a $20 \%$ sucrose solution (in $0.1 \mathrm{M}$ phosphate buffer, $\mathrm{pH}$ 7.4) for 6-8 h, with continuous agitation. Sagittal plane frozen sections $(25 \mu \mathrm{m}$ thin) were cut on a freezing microtome (Reichert, USA) and used as free-floating sections in immunohistochemistry. 
3.1.Pretreatment with glutamate receptor antagonists

The NMDA receptor antagonists MK-801, amantadine (Sigma, St. Louis, MO) were dissolved in saline. The AMPA receptor antagonist GYKI-52466 (Sigma, St. Louis, MO) was dissolved in 50\% DMSO (DMSO: dimethyl-sulphoxide; Sigma, St. Louis, MO; de Sarro et al., 1995; Weiczner et al., 2008). The animals were divided into six groups with four animals per group. In the first three groups the animals were pretreated with glutamate receptor antagonists MK-801 (2 mg/kg), amantadine (50 mg/kg), GYKI-52466 (50 mg/kg). After the pretreatment (15 min following the antagonist administration) the convulsant 4AP was administered intraperitoneally (dose: $5 \mathrm{mg} / \mathrm{kg}$ ). In the second three groups the animals received the solvent of the antagonists and 15 min later the 4-AP. The experiments were finished $2 \mathrm{~h}$ after the 4-AP injection. The seizure symptoms were observed and the latencies of the first generalized tonic-clonic seizure (GTCS) were measured. At the end of the observation ( $2 \mathrm{~h}$ following the 4-AP injection) the rats were deeply anesthetised with diethyl-ether (Fluka). The chest was opened, the aorta was cannulated and the animals were perfused with fixative, which contained $4 \%$ paraformaldehyde in $0.1 \mathrm{M}$ phosphate buffer, $\mathrm{pH}$ 7.4. After the transcardiac perfusion the brains were dissected and postfixed in the same fixative for $1 \mathrm{~h}$ at room temperature. The vermis was separated and soaked in $20 \%$ sucrose solution (in 0,1 phosphate buffer, $\mathrm{pH}$ 7.4.) for 10-12 h. Sagittal plane frozen sections ( $25 \mu \mathrm{m}$ thick) were cut on a freezing microtome and used as free-floating sections in immunohistochemistry.

\subsection{Behavioural studies}

Ten adult male Wistar rats were used in every group. The NMDA receptor antagonists MK-801 and amantadine (Sigma, St. Louis, MO) were dissolved in saline. The GYKI52466 (Sigma, St. Louis, MO) was dissolved in 50\% DMSO (de Sarro et al., 1995; Weiczner et al., 2008). The seizures were induced with a single intraperitoneal (i.p.) injection of 4-AP which was dissolved in physiological saline $(5 \mathrm{mg} / \mathrm{kg} 4-\mathrm{AP}$ in 0,67 mg/ml vehicle). This 4-AP dose proved to be epileptogenic (Mihály et al., 1990; 2001; Tóth et al., 2015). The animals were pretreated with glutamate receptor antagonists MK-801 (2 mg/kg), amantadine (50 mg/kg) and GYKI-52466 (50 mg/kg) intraperitoneally. 
After the pretreatment (15 min later) the convulsant agent 4-AP was administered intraperitoneally $(5 \mathrm{mg} / \mathrm{kg})$. In the control groups animals received the solvent of the antagonists and the 4-AP. The seizure symptoms were registered: the latencies of the first GTCS were statistically investigated with one-way analysis of variance (ANOVA), whereas the incidence of the generalized tonic-clonic seizure was analyzed by Fisher's exact test using SPSS 9.0 statistical software. During the analysis, the pretreated groups were compared to the control group (4-AP injected only), and the significance level was $\mathrm{p}<0.05$.

\subsection{Immunohistochemistry}

Polyclonal c-fos antibody (\#sc-52, raised in rabbit; Santa Cruz Biotechnology, Santa Cruz, CA, USA) and the peroxidase-antiperoxidase (PAP) method were used. The sections were pre-treated with $1.5 \% \quad \mathrm{H}_{2} \mathrm{O}_{2}$ and rinsed in $0.1 \mathrm{M}$ phosphate-buffered saline (PBS) containing $0.2 \%$ Triton X-100 (Sigma-Aldrich). They were then incubated in 20\% normal pig serum, next in primary c-fos antibody (1:1,000 in 20\% normal pig serum in PBS and $0.2 \%$ sodium azide), and then in donkey anti-rabbit IgG (1:40; Jackson Immuno-Research, West Grove, PA, USA). The secondary antibody was detected with the PAP technique (PAP complex diluted to 1:1,000; Jackson Immuno-Research). The peroxidase reaction was localized with diaminobenzidine tetrahydrochloride (DAB; Sigma-Aldrich), yielding a brown reaction product and with nickel chloride containing diaminobenzidine tetrahydrochloride (DAB; Sigma-Aldrich), yielding a black reaction product. The sections were mounted on glass slides and covered with Entellan ${ }^{\circledR}$ (Fluka).

3.4.Morphometric analysis of the immunohistochemical data

From every animal, 5 sagittal plane sections of the vermis and the hemispheres were selected. Areas of interest (AOIs) for counts of c-fos immunoreactive (c-fosIR) neuronal nuclei were from every cerebellar lobule (I-X), from the granule cell layer. Within each 
AOI, the c-fosIR cell nuclei were counted using a Nikon Eclipse 600 microscope equipped with a SPOT RT Slider digital camera (1600 x 1200 dpi in 8 bits), with the help of Image Pro Plus 4.5 morphometry software (Media Cybernetics, Bethesda, MD, USA). Following background subtraction, the threshold was determined so that all labelled nuclei could be recognized. The counting was performed blindly of the animal's treatment. The AOI size was the rectangular image capturing field of the camera. Cell counts were done using a 10x objective, and the AOI $\left(0.25 \mathrm{~mm}^{2}\right)$ included a relatively large area of the granule cell layer. As to the identification of the cerebellar lobules, we used the nomenclature of Jan Voogd (Voogd, 2004). The data were analysed statistically comparing sets of measurements obtained with the same magnification. The cell counts in the first experiments were normalised to one $\mu \mathrm{m}^{2}$ (Figs 4,7) and in the other experiments to one $\mathrm{mm}^{2}$ (Fig 5). Differences in the number of c-fosIR cells in the control and the convulsing animals were analysed with one way analysis of variance (ANOVA), followed by the Bonferroni post hoctest. A significance criterion of 0.05 was used. The statistical analysis was performed with the SPSS 9.0 software (SPSS, IBM, Chicago, IL, USA).

\subsection{Western blotting}

Animals (MCPL: 7 animals; SOC: 6 animals)were deeply anesthetized with diethyl-ether, decapitated and the cerebellum was removed on ice. The two hemispheres and the vermis were separated and quickly frozen in liquid nitrogen. The samples (hemispheres and vermis, separately) were homogenized in ice cold buffer containing $0.1 \mathrm{mM}$ phosphatebuffered saline (PBS), 5 mM EDTA, protease inhibitors (Complete Mini, F. Hoffmann-La Roche Ltd., Switzerland), $1 \mathrm{mM}$ phenylmethylsulphonyl fluoride (PMSF) and 1\% Triton $\mathrm{X}-100$.

SDS-PAGE was performed according to the method of Laemmli (1970) with $12 \%$ (w/v) polyacrylamide in the separating gel. Proteins were then transferred to PVDF membranes (Bio-Rad Laboratories, Hercules, CA, USA). After being blocked in PBS containing 5\% (w/v) low-fat milk powder, blots were exposed to antibodies against c-fos (sc-52) in 1:1,000 dilution, or beta actin (sc-47778) in 1:10,000 dilutions. Antibodies and washing steps were carried out in PBS containing $1 \%(\mathrm{w} / \mathrm{v})$ low-fat milk powder and $0.1 \%$ Tween20 detergent. Bound antibodies were detected with horseradish peroxidase labelled antimouse $\operatorname{IgG}$ (sc-2031; in 1:10,000) or anti-rabbit IgG (sc-2030; in 1:2,000), and the reaction was detected with enhanced chemiluminescence reagent as a substrate for peroxidase, and 
captured on x-ray film. The film was later scanned and analysed with ImageJ software (National Institutes of Health, Bethesda, MD, USA). Antibodies were purchased from Santa Cruz Biotechnology (Santa Cruz, CA, USA), other chemicals from Sigma-Aldrich (St. Louis, MO, USA). Results were analysed with one way analysis of variance (ANOVA), followed by the Bonferroni post hoc test.

\subsection{Neurosurgery}

The animals $(n=15)$ were anesthetized with the i.p. injection of a mixture of ketamine ( 80 $\mathrm{mg} / \mathrm{kg})$, pentobarbital $(20 \mathrm{mg} / \mathrm{kg})$ and atropine $(0.01 \mathrm{mg} / \mathrm{kg})$. The heads were fixed in a stereotaxic instrument. The skull was opened in the retroauricular region on the left side with a dental drill. The left middle cerebellar peduncle (MCP) was exposed through the dissection of the flocculus. The MCP was destroyed with an electro-coagulator (Diatrom80; Fazzini, Italy). The skull window was closed with the bone- and muscle flaps and the skin was sutured. (Fig. 1.) Sham operated control (SOC) animals ( $n=15)$ underwent craniotomy, but the dura mater was not opened. After the surgery, the animals displayed transient vestibular symptoms, which gradually disappeared in 1-2 days. The animals survived 2 weeks following the surgery, then they were treated with 4-AP, as described above. Following the seizure experiments c-fos immunohistochemistry and cell counts were performed, as described above. In order to test the effects of the MCP lesion (MCPL), brains were investigated with standard histological and immunohistochemical methods. Two brains were embedded in paraffin wax, coronal plane $5 \mu \mathrm{m}$ thick sections were cut at the level of the MCPL and stained with hematoxylin and eosin, in order to visualize the extent of MCPL. Another group of animals (3 MCPL and 3 SOC animals) were anesthetized and their brains fixed through transcardiac perfusion, as described above. Coronal plane frozen sections at the level of the MCP were cut from the whole cerebellum and stained with glial fibrillary acidic protein (GFAP) antibody and synapsin I antibody, as described previously (Kopniczky et al., 2005). We investigated the extent of gliosis (GFAP staining) and the extent of the terminal axonal degeneration (synapsin I staining) (Kopniczky et al., 2005). 
Operated animals (4 MCPL and 4 SOC animals) were treated with 4-AP (as described above) 14 days after the surgery. C-fos immunoreactivity of the cerebellar hemispheres was investigated with immunohistochemistry of c-fos protein $2 \mathrm{~h}$ after the 4-AP administration (the fixation, sectioning and immunostaining protocol was described above). Another group of the operated animals (6 MCPL and 6 SOC) was used to detect cfos protein with Western blotting (the blotting protocol was described above). Statistical analysis on the operated animals was identical to previous descriptions.
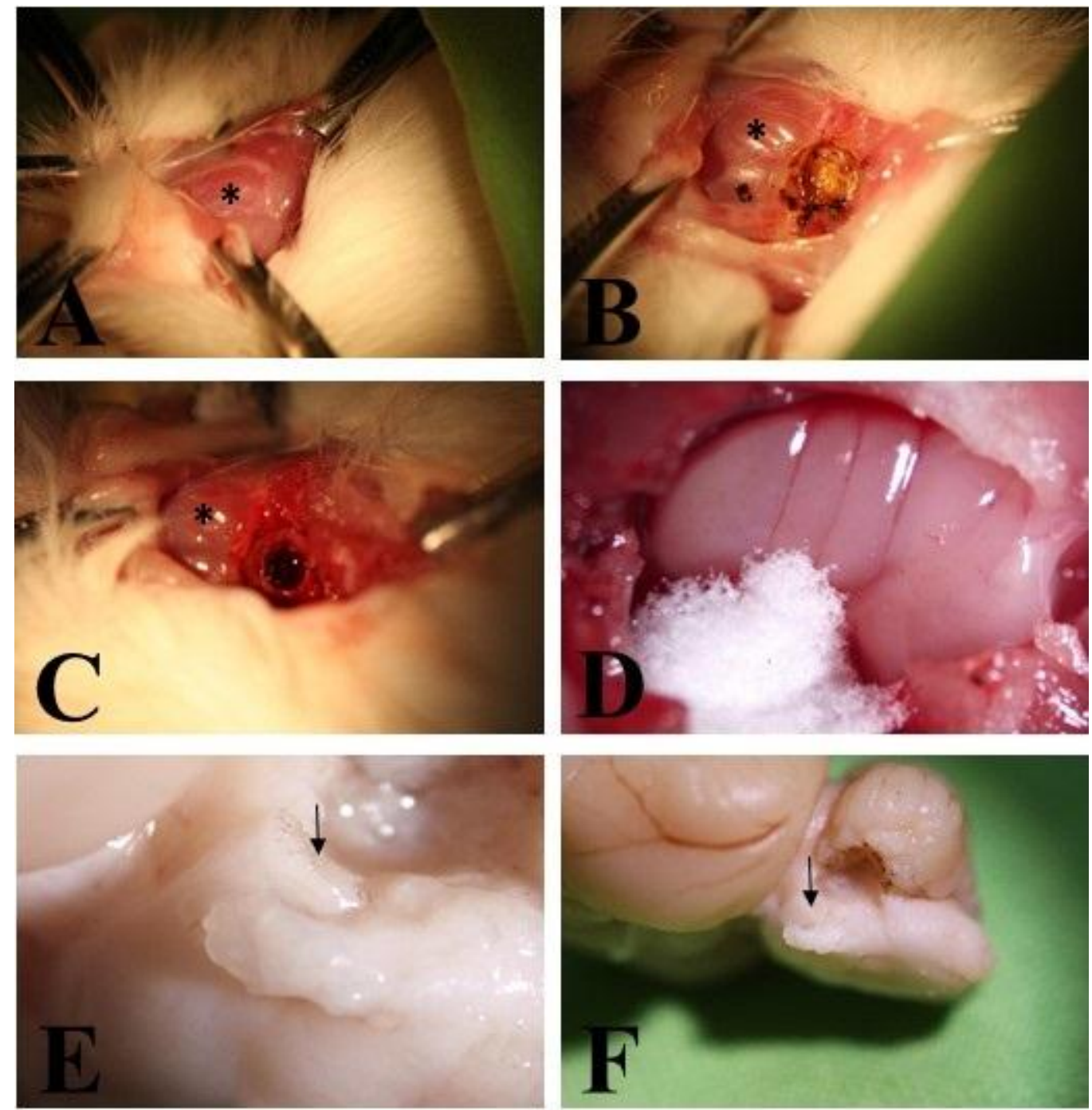

Fig. 1: The steps of the MCP ablation procedure. After a skin incision (A) in the retroauriclar region the temporalis muscle $(*)$ was cut and a muscle flap was made (B). The skull was opened on the left side with a dental drill (C). The left middle cerebellar peduncle (MCP) was exposed through the dissection of the flocculus. The MCP was destroyed with an electro-coagulator (Diatrom80; Fazzini, Italy). After haemorrhage control with Spongostan (D) the skull window was closed with the bone- and muscle flaps and the skin was sutured. The arrows show the cutted MCP following fixation. 


\section{RESULTS}

\subsection{Animal behaviour}

The symptoms and the electroencephalography of the motor seizures elicited by the 4-AP injection have been described in detail (Mihály et al., 1990; 2005). We observed similar symptoms and finally the generalized tonic-clonic seizure (GTCS) in every animal (Fig. 2.). The latency of the GTCS was $32.5 \mathrm{~min}$ in an average of 10 animals (see also Mihály et al., 1990). The symptoms began with generalized muscle tremor, which increased and led to a very short "wild running" phase, then the animal lost equilibrium control and the GTCS followed. The tonic phase of the GTCS consisted of rigid extension of the limbs and prolonged contraction of the trunk muscles. Some seconds later, this tonic contraction of the musculature was followed by a short relaxation, then by strong clonic limb movements, while the animal lies on its side. Following the GTCS, a quiet postictal period followed (1$8 \mathrm{~min}$ ). During this time the animal laid on its side without movements. The sequence of the motor symptoms could repeat once more. At the end of the seizures the animals experienced a postictal depression and then recovered without symptoms. This sequel (with the two GTCS periods) required 90-100 min.

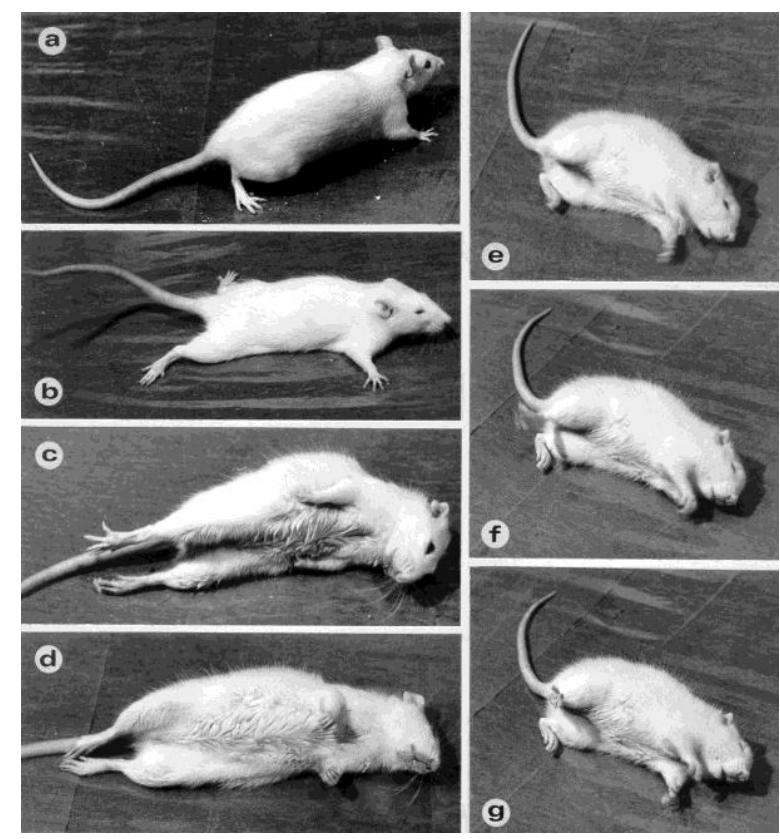


Fig. 2: The symptomatic appearance of the 4-AP-induced acute seizure activity. Increased exploring activity, tremor of vibrissal and masticatory muscles (a). Abducted position of hind limbs (b). GTCS with extension and hypersalivation (c,d), sometimes introduced by wild running. The clonic phase, with simultaneous tenebrosity (e). After 50-60 min, the seizure activity gradually decreased (f), most of the animals regenerate after $90 \mathrm{~min}(\mathrm{~g})$. In some cases GTCS can lead to the death of the animal. (Photographs: Department of Anatomy, Szeged).

Following the ablation of the MCP, the animals displayed minor motor deficits (mainly tottery gait), which disappeared in 1-2 days. No neurological deficits were detected one week after the surgery. The injection of 4-AP precipitated motor convulsions and GTCS: however, the latency of the GTCS was longer: it was $41.5 \mathrm{~min}$ in the average of $10 \mathrm{MCPL}$ animals. We did not perform statistical analyses of the seizure symptoms and latencies in MCPL animals. SOC animals did not present any symptoms following the surgery.

In those animals which were pretreated with MK-801 the latency of the GTCS increased significantly (Table 1). Amantadine and GYKI-52466 did not influence the latency of the GTCS. However, the number of the animals displaying GTCS decreased in every pretreated group: in the group pretreated with MK-801 only $80 \%$ of the animals, in the amantadine group only $70 \%$ of the animals and in the GYKI-52466 group only $60 \%$ of the animals displayed GTCS (Table 1). Animals without GTCS displayed only shivering, minor limb clonuses and increased exploratory activity. In the control (4-AP treated) group $100 \%$ of the animals displayed GTCS.

\begin{tabular}{lccc}
\hline \multicolumn{1}{c}{ Treatment } & $\begin{array}{c}\text { Animal } \\
\text { number/group }\end{array}$ & $\begin{array}{c}\text { GTCS latency } \\
(\mathrm{min})\end{array}$ & $\begin{array}{c}\text { Animals } \\
\text { displaying GTCS }\end{array}$ \\
\hline 4-AP (control) & 10 & $32,21 \mathrm{~min}$ & $10 / 10$ \\
4-AP + MK-801 & 10 & $41,37 \mathrm{~min}$ & $8 / 10$ \\
4-AP + Amantadine & 10 & $27,16 \mathrm{~min}$ & $7 / 10$ \\
4-AP + GYKI 52466 & 10 & $39,56 \mathrm{~min}$ & $6 / 10$ \\
\hline
\end{tabular}

Table 1: Behavioural analysis of the experimental animals treated with 4-AP. The latency time was 
measured from the administration of 4-AP. In every group there were 10 animals. The asterix notes the significant difference between latency times of control group (treated only with 4-AP) and the pretreated groups. In the control group the GTCS occured in $100 \%$ of the animals. In case of the second group (pretreated with MK-801) the GTCS latency was significant longer compared with control animals. In this group the GTCS occured in $80 \%$. In the other groups (pretreated with GYKI-52466 and Amantadine) the latency time was longer but there was no significant difference compared with the control group [*p<0,05 (ANOVA)].

4.2 Number of c-fos immunoreactive cell nuclei in the cerebellar vermis following 4-AP induced seizures

The GTCS caused by the 4-AP induced intensive c-fos immunostaining in the granule cell layer of the cerebellar hemispheres and vermis. The c-fos immunostaining following the 4AP injection showed characteristic appearance in the vermal lobules: scattered c-fosIR cell nuclei were detectable in the molecular layer and in some Purkinje cells, but most of the labelled cell nuclei were present in the granular layer (Fig. 3). In the present study, only the granular layer has been quantified: the c-fosIR nuclei were counted according to the lobules. Control animals displayed a very small number of c-fosIR nuclei, while the 4-AP treated animals showed a large increase of the c-fos expression (Fig. 3).

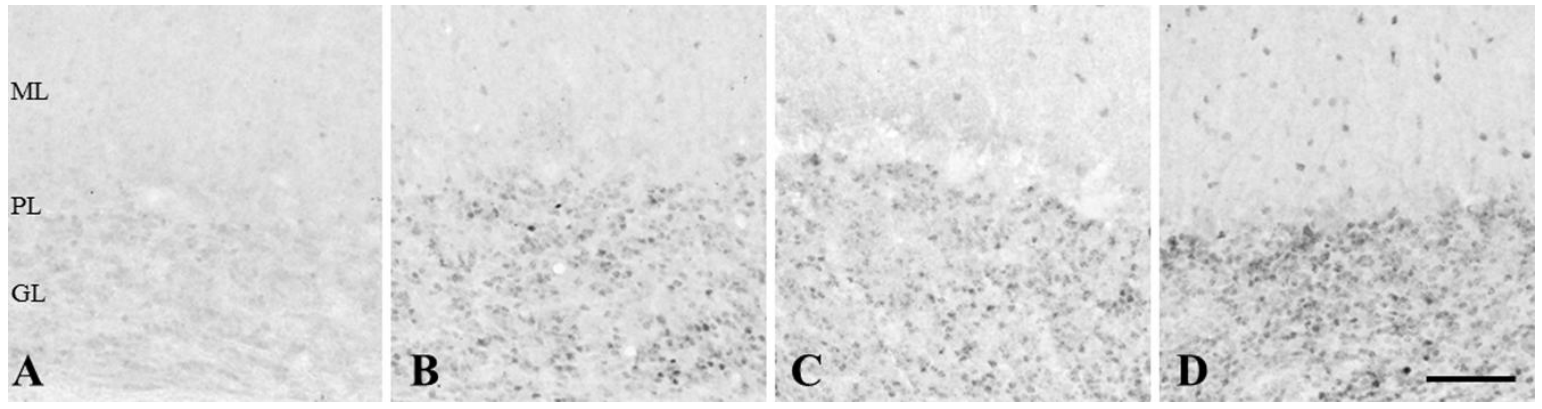

Fig. 3. Immunohistochemistry of c-fos protein in the cerebellar vermis.

Low magnification pictures of the distribution of c-fosIR cell nuclei in the cerebellar vermis of the control (A), and the 4-AP treated animals at $1.5 \mathrm{~h} \mathrm{(B),} 2 \mathrm{~h}(\mathrm{C})$ and $3 \mathrm{~h}(\mathrm{D})$ post injection. Layers are indicated by the abbreviations: ML molecular layer, PL Purkinje cell layer, GL granular layer. Scale bar $=10 \mu \mathrm{m}$.

The number of c-fosIR nuclei in the granular layer was raised significantly at $1.5 \mathrm{~h}$ and reached a maximum at $3 \mathrm{~h}$. The numbers of c-fosIR nuclei were significantly higher (compared to the control -4B) at $1.5 \mathrm{~h}$ in every vermal lobule (Fig. 4). The numbers 
gradually increased further at $2 \mathrm{~h}$ and reached a maximum at $3 \mathrm{~h}$ (Fig. 4A). The different lobules (I-X) were activated similarly, except lobule V, where maximum activation was seen at $2 \mathrm{~h}$ and the c-fosIR values decreased at $3 \mathrm{~h}$. The decrease was small, but significant (Fig. 4A). Investigation of the summated counts $(1.5 \mathrm{~h}, 2 \mathrm{~h}$, and $3 \mathrm{~h})$ from every lobule of the vermis displayed a continuous increase from $1.5 \mathrm{~h}$ to $3 \mathrm{~h}$ with very significant differences between each other (Fig. 4C).

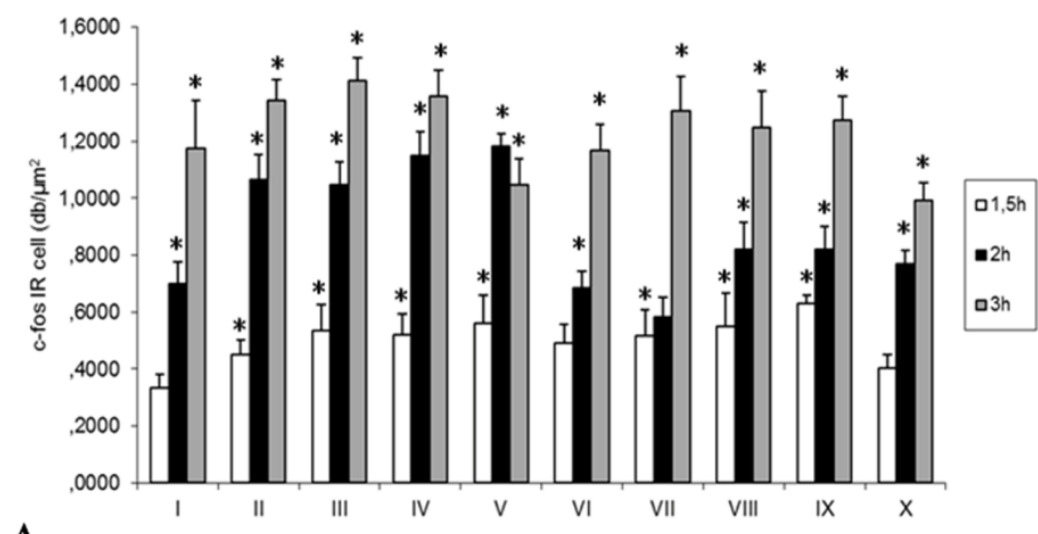

A

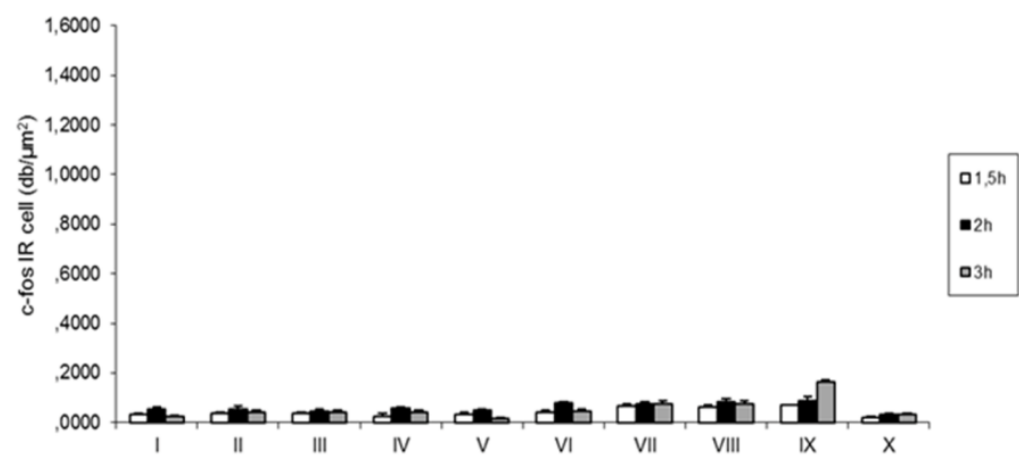

$\mathrm{B}$

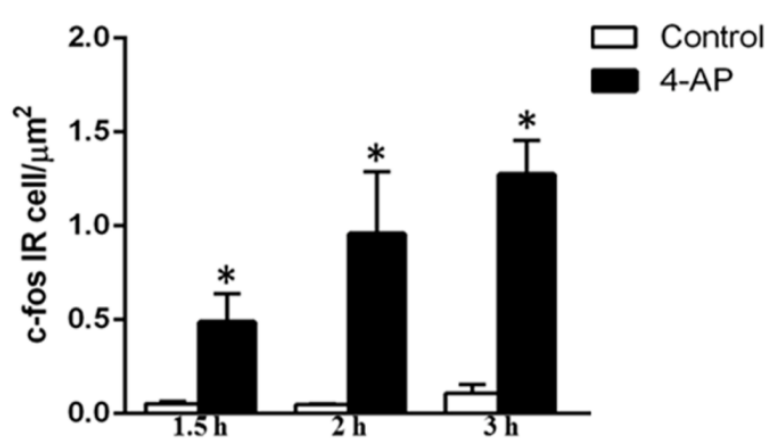

$\mathrm{C}$ 
Fig. 4. Quantitative evaluation of c-fosIR cell nuclei numbers in vermal lobules I-X at $1.5 \mathrm{~h}$ (white columns), $2 \mathrm{~h}$ (black columns) and $3 \mathrm{~h}$ (grey columns) following the 4-AP injection. Ordinate: cell number per one $\mu \mathrm{m}^{2}$; abscissa: lobules numbered from I to X.

IR positive cells were counted in the granular layer of each cerebellar lobule. The number of immunoreactive nuclei increased significantly at $1.5 \mathrm{~h}$ and reached maximum at $3 \mathrm{~h}$ after the 4 -AP treatment (A). Control animals displayed low numbers of c-fosIR cell nuclei (B). The vermal lobules were activated similarly, except lobule V (A). The summated counts (C) from every lobule display highly significant statistical differences between each time point (white columns: controls; black columns: convulsing animals). Significant differences are shown by asterisks $\left({ }^{*} \mathrm{p}<0.005\right)$. The standard error of the mean (SEM) is shown on the top of the columns.

4.3 Number of c-fos immunoreactive cells in the cerebellar vermis following pretreatment with glutamate receptor antagonists

In our previous study we observed the activation pattern of vermal granule cells following 4-AP treatment (Tóth et al., 2015). Most of the labeled cell nuclei were detectable in the granular layer, therefore the granular layer was investigated in these experiments. According to our previous experiments (Tóth et al., 2015) the number of c-fos-IR cell nuclei raised significantly at $1.5 \mathrm{~h}$ and reached maximum at $3 \mathrm{~h}$ (Tóth et al., 2015), therefore the $2 \mathrm{~h}$ survival time was choosen for countings in these pharmacological experiments. C-fosIR cell nuclei were counted according to every vermal lobule. In the control animals (treated only with 4-AP) the pattern and dynamics of the granule cell activation were similar to that previously observed and described (Tóth et al., 2015). A large number of c-fos positive cells were detected in every vermal lobule in the granular layer of the cerebellar cortex $2 \mathrm{~h}$ following the 4-AP injection (Fig. 5A). This number of the c-fosIR cell was significantly greater than that in non-convulsing control animals (Tóth et al., 201; Krisztin-Péva et al., 2019). Pretreatment with GYKI-52466, MK-801 and amantadine resulted in a significant decrease of the number of c-fosIR positive granule cells compared to animals treated only with 4-AP (Fig. 5 B,C,D ). Decreases of the c-fosIR granule cell numbers were similar in the anterior and posterior lobes and in every vermal lobule. The summated counts of the entire vermis also displayed significant differences: decreases of the c-fosIR cell nuclei in the animals pretreated with the NMDA- and AMPA antagonists were highly significant (Tóth et al., 2018). 

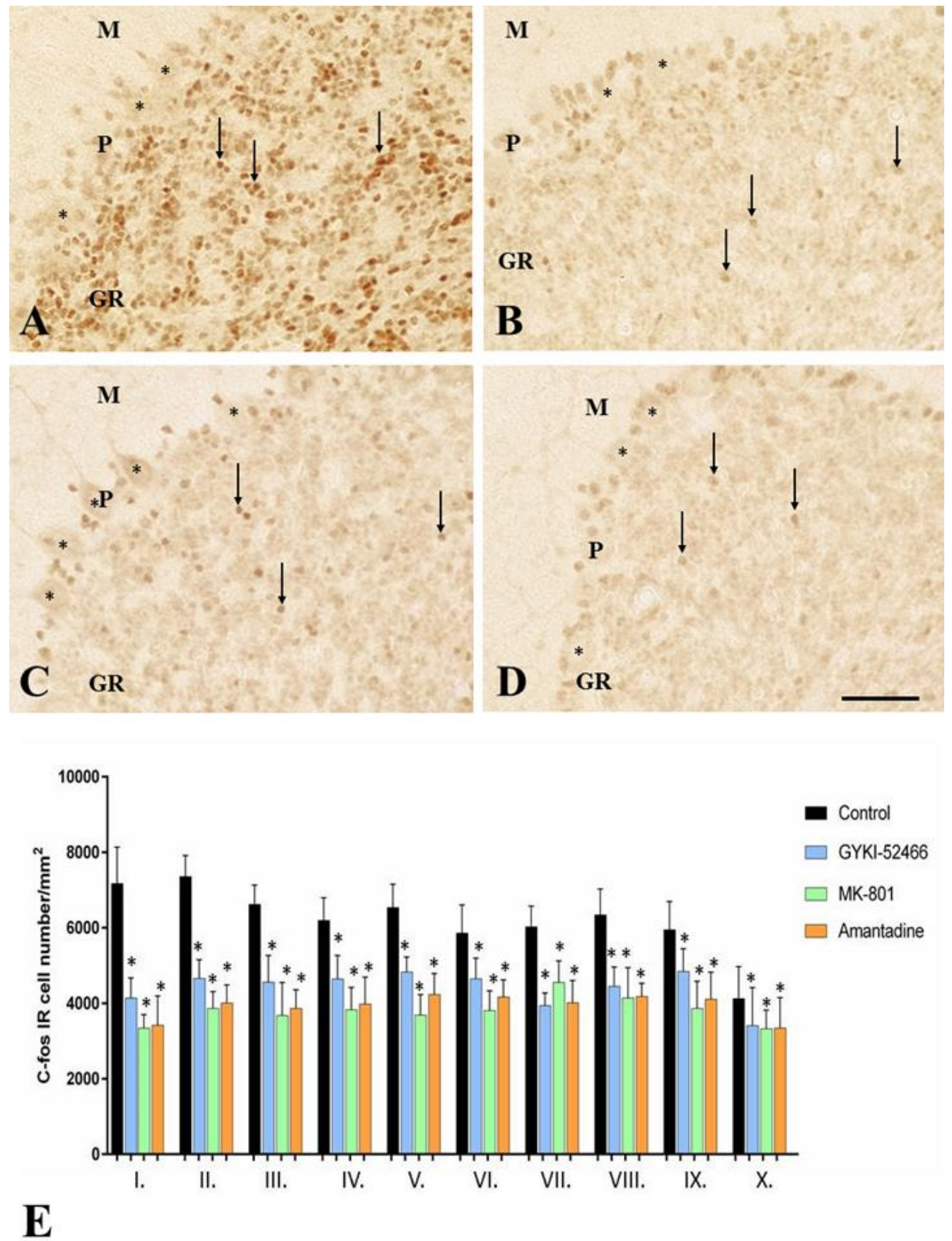

Figure 5. Immunohistochemistry of c-fos protein in the cerebellar vermis 2 hours following 4-AP administration. 40x magnification images of the distribution of c-fos immunpositive granule cell nuclei (A) treated only with 4-AP; (B) GYKI 52466 tretreatment; (C) MK-801 pretreatment; (D) Amantadine pretreatment. Layers are indicated by abbreviations: $\mathrm{M}$ molecular layer, P Purkinje cell layer, GR granular layer. Arrows show the immunopositive cell nuclei in the granular layer. The Purkinje cells are showh by small asterisks. Scale bar $=50 \mu \mathrm{m}$.

(E) Quantitative evaluation of c-fosIR cell nuclei numbers in vermal lobules I-X at $2 \mathrm{~h}$ after the 4AP injection. Ordinate: cell number per one $\mathrm{mm}^{2}$; abscissa: lobules numbered from I to X. IR positive cells were counted in the granular layer of each cerebellar lobule. The number of immunoreactive nuclei decreased significantly. Control animals treated with 4-AP displayed high numbers of c-fosIR cell nuclei. Every pretreatment caused a significant decrease of c-fos expression compared to control group. Significant differences are shown by asterisks $\left({ }^{*} \mathrm{p}<0.005\right)$. The standard error of the mean (SEM) is shown on the top of the columns. 
4.4 C-fos immunoreactivity and Western blotting after transection of the middle cerebellar peduncle

In order to examine the effect of the MCPL we used the immunohistochemical analysis of c-fos expression of the cerebellar granule cells in MCPL and SOC animals (Fig. 6A,B,C). The animals were injected with 4 -AP and $2 \mathrm{~h}$ after the injections quantitative immunohistochemistry was performed (see Methods). The number of c-fosIR nuclei of SOC animals did not differ from that seen in intact, non-operated animals (Fig. 6A). Quantitative examination proved that the c-fos expression of granule cells decreased significantly in the operated hemisphere of MCPL animals compared to the SOC animals and to the non-operated hemisphere of the MCPL animals (Fig. 7A).
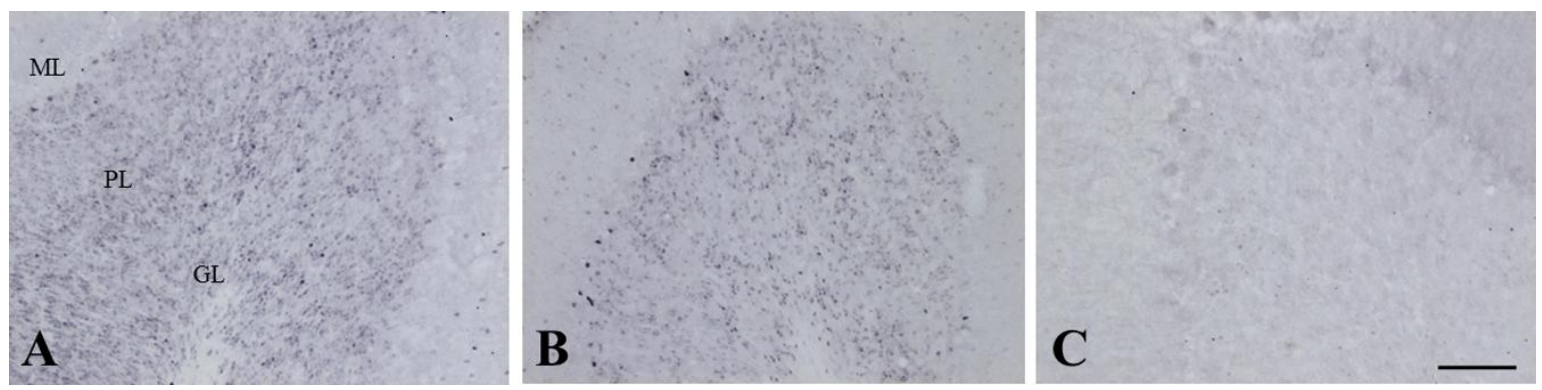

Fig. 6 Immunohistochemistry of c-fos $2 \mathrm{~h}$ after 4-AP injection in the cerebellar hemispheres of SOC and MCPL animals on coronal plane sections. Density of c-fosIR cell nuclei following 4-AP induced seizures in SOC animal (A), non-operated side of MCPL animal (B) and operated side of MCPL animal (C) (ML: molecular layer; GL: granular layer; PL: Purkinje cell layer; WM, white matter). Scale bar $=100 \mu \mathrm{m}$.

We also tested the effect of the MCPL on the c-fos protein content with Western blotting of cerebellar tissue from control and convulsing animals. The results showed that the c-fos protein levels decreased significantly in the vermis and in both hemispheres (in the operated and in the contralateral hemispheres) of the MCPL animals, compared to those of the SOC animals ( $<0.001)$. The decrease in the operated hemisphere was larger than that in the contralateral one (Fig. 7B). No significant differences in the c-fos contents were detected between the operated and non-operated (contralateral) hemispheres in the 
MCPL animal, although the operated side contained a slightly weaker c-fos signal (Fig. 7B).

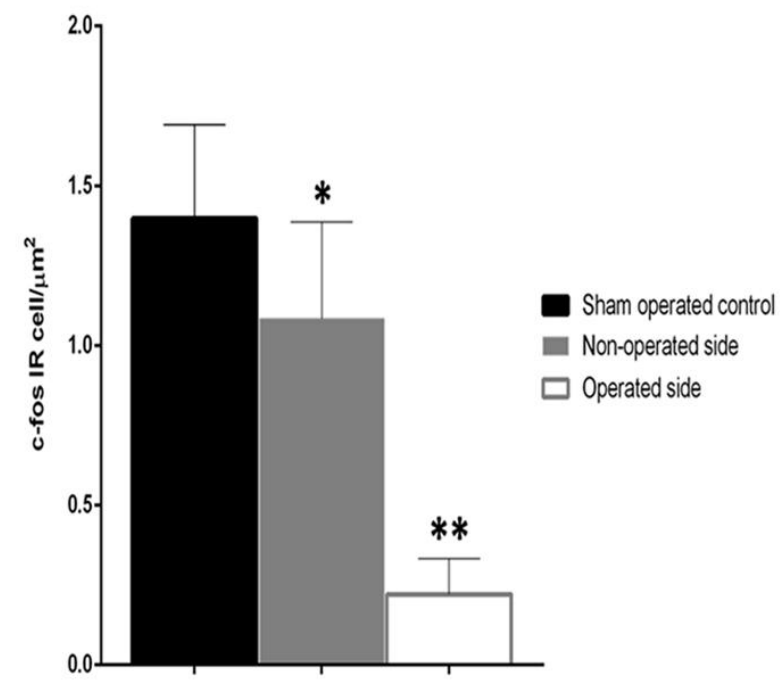

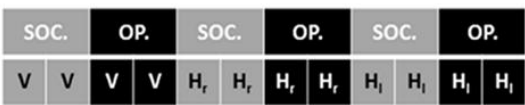

A
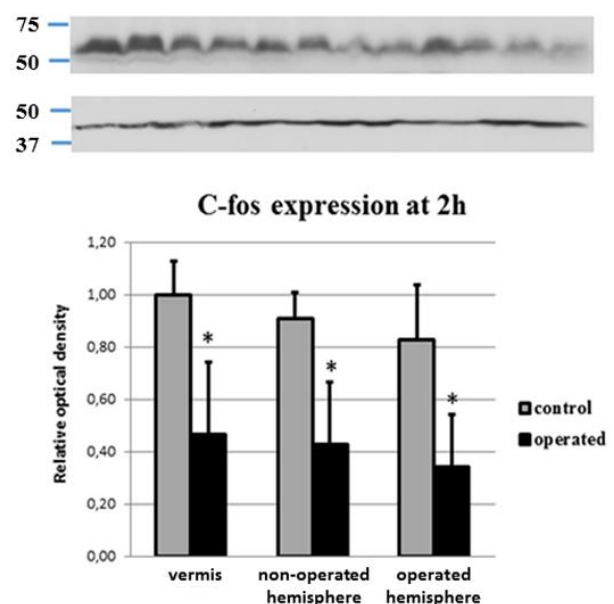

B

Fig. 7 Quantitative analysis of c-fosIR cell nuclei in the posterior lobe of the hemispheres (A) and the results of Western blotting of the c-fos protein (B). A: Quantitative analysis of the 4-AP induced alterations of c-fosIR cell numbers in the operated cerebella (white and grey columns) compared to the SOC animals (black column), $2 \mathrm{~h}$ after the 4-AP treatment. The c-fosIR cell number decreased significantly on the operated side of MCPL animals (white column). A significant decrease of c-fosIR cell number was also seen in the non-operated hemisphere of the MCPL animals (grey column) $(* \mathrm{p}<0.005 ; * * \mathrm{p}<0.001)$. B: Western blotting of $\mathrm{c}$-fos protein $2 \mathrm{~h}$ after 4-AP injections in the right and left hemispheres and vermis. Upper part of the figure displays the blots of c-fos (upper row) and beta actin (lower row). Molecular weights are shown (75 kDa, 50 $\mathrm{kDa}, 37 \mathrm{kDa}$ ). SOC: sham operated control animals; OP: operated animals; V: vermis; $\mathrm{H}_{\mathrm{r}}$ : right hemispheres; $\mathrm{H}_{1}$ : left (lesioned) hemisphere. The graph shows the densitometry evaluation of the blots: grey columns are representing the controls (SOC animals), black columns are representing the vermis of MCPL animals, the non-operated (right) hemisphere of the MCPL animals and the operated left hemisphere of the MCPL animals $(* p<0.005)$.

4.5 Histology and immunohistochemistry cerebellar cortex after the transection of the middle cerebellar peduncle 
Thin coronal sections of the cerebellum and brainstem revealed that as the result of neurosurgery, the MCP was completely destroyed. On the side of the surgery, the flocculus was also absent (Fig. 8B). No other neuropathological damages and no signs of inflammation were observed in the surgery location (Fig. 8B).

The normal cerebellar cortex displays strong synapsin I immunoreactivity in the granular layer (Fukaya et al., 1999). Scattered synapsin I immunoreactivity was also seen in the molecular- and Purkinje cell layers (Fig. 8C). On the side of the MCPL synapsin I immunoreactivity disappeared from the granular layer of the cerebellar cortex (Fig. 8C). The densitometry measurements of the cerebellar layers strongly supported this light microscopic observation (Fig. 8E). The contralateral cerebellar cortex of the MCPL animals, and the cerebellar cortex of SOC animals displayed normal synapsin I staining (Fig 8E). The GFAP immunoreactivity was strong on the operated side: the radial glia and scattered astrocytes contained large amounts of GFAP in every cerebellar cortical layer. The contralateral MCPL and SOC cerebellar cortices contained much less immunostaining (not shown). No densitometry evaluation of the GFAP staining was performed.
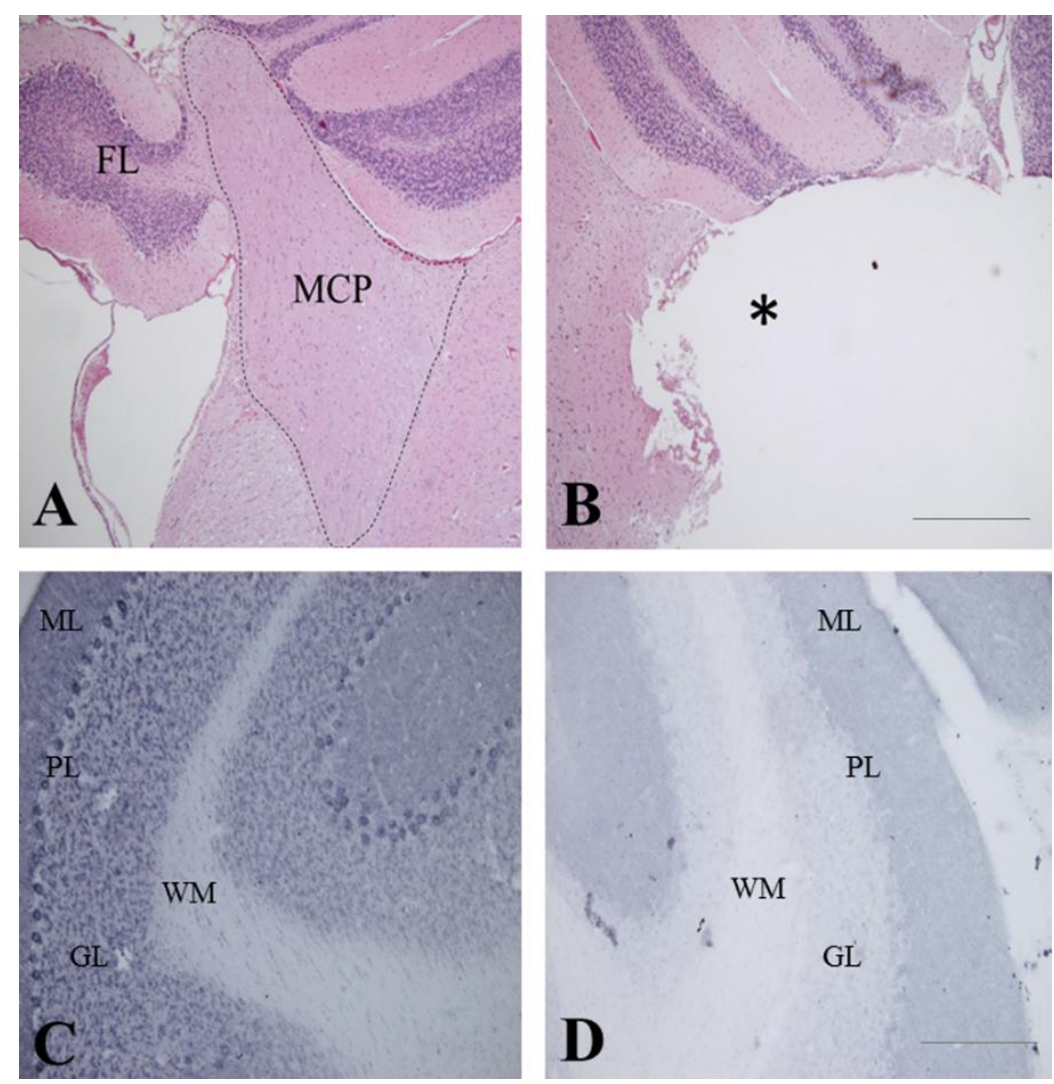


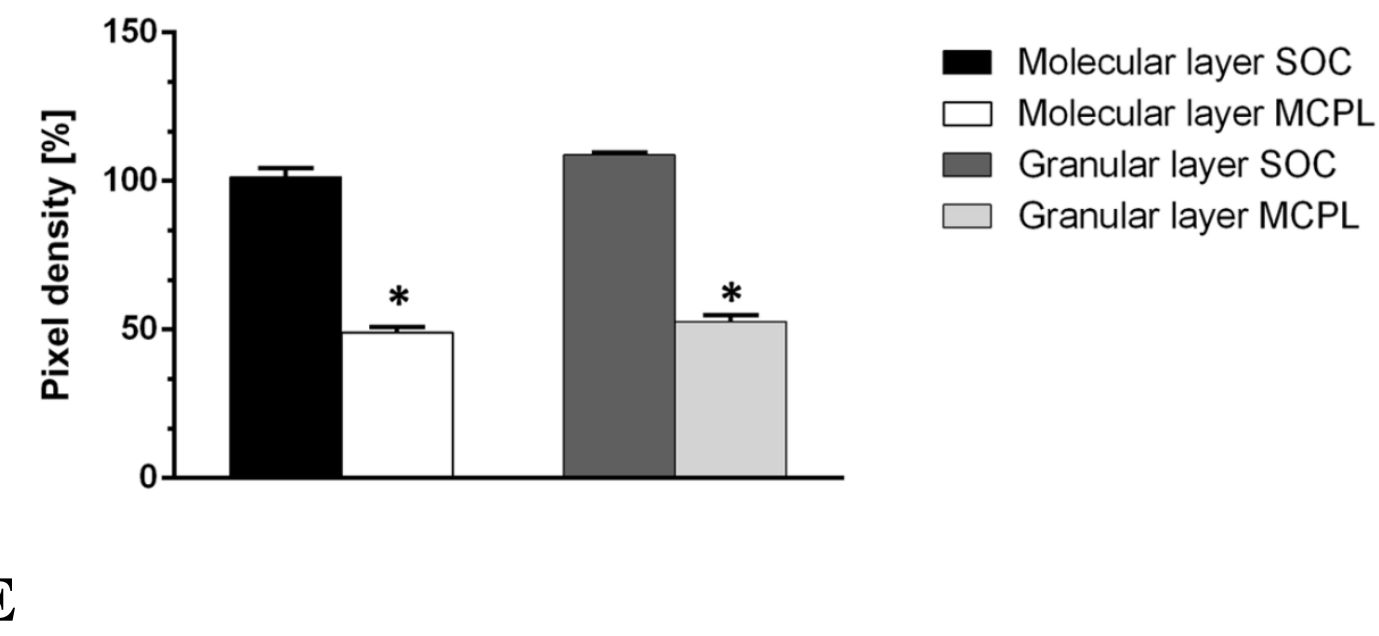

Fig. 8 Histology and immunohistochemistry of the cerebellum following MCP transection.

Coronal plane sections from the sham operated controls (A) and from the operated animals (B) stained with haematoxylin-eosin prove the complete transection of the MCP (asterisk on B). FL: flocculus. Bar: $500 \mu \mathrm{m}$. C,D: Synapsin I immunohistohemistry of SOC (C) and MCPL (D) brains. Note the marked reduction of the synapsin I immunoreactivity in the molecular layer (ML) and granular layer (GL) on the side of the lesion (E). ML: molecular layer; GL: granular layer; PL: Purkinje cell layer; WM: white matter. Scale bar $=100 \mu \mathrm{m}$. $\left({ }^{*} \mathrm{p}<0.005\right)$

\section{DISCUSSION}

5.1.C-fos expression is a reliable marker of neuronal hyperactivity

Seizures induced by chemical convulsants lead to a rapid, massive and transient induction of c-fos mRNA and protein in several brain regions (Gass et al., 1992; Herdegen and Leah, 1998; Mihály et al., 2005). The postsynaptic c-fos mRNA expression correlates well with the presynaptic release of excitatory neurotransmitters (Labiner et al., 1993), and the detection of the c-fos protein is therefore suitable for the histological mapping of neuronal hyperactivity (Labiner et al., 1993; Mihály et al., 1997; 2001). Our previous studies proved that c-fos protein is a reliable marker of neuronal hyperactivity in 4-AP induced acute seizures (Mihály et al., 2001, 2005; Szakács et al., 2003; Kopniczky et al., 2005). During the 4-AP seizure the increase of the number of c-fosIR cell nuclei displayed a characteristic 
pattern: maximum numbers of the c-fosIR cells were seen at 1 hour after 4-AP treatment in the neocortex, dentate gyrus and striatum (Kovács et al., 2003; Mihály et al., 2001; 2005). According to our RT-PCR measurements in the neocortex, the $c$-fos mRNA expression dynamics showed a similar pattern with maximum expression at $1 \mathrm{~h}$ (Mihály et al., 2005).

5.2 C-fos expression pattern of the cerebellar granule cells following 4-AP induced seizures

The effects of 4-AP-induced seizure were similar in the cerebellar cortex: strong c-fos protein expression was detected in the granular layer. Important observation of the present experiments was that the activation of the cerebellar granule cells lasted significantly longer than the activation of the hippocampal granule cells (Mihály et al., 2001), the activation of neurons of the striatum (Kovács et al., 2003) and the activation of the neurons of the neocortex (Mihály et al., 2005). The cerebellar granule cell is a glutamatergic neuron, which has NMDA and AMPA receptors on its dendritic tree (Geurts et al., 2003; Koutsuraki et al., 2013). The granule cell dendrites receive strong afferentation from the glutamatergic mossy fiber system (Hirano, 2013). The NMDA-mediated postsynaptic effects include $\mathrm{Ca}^{++}$influx and plasticity changes (Cull-Candy et al., 2001). The AMPA effects include desensitization (Xu-Friedman and Regehr, 2003) because of the large size of the mossy axon terminal. However, the participation and exact contribution of the AMPA- and NMDA receptors to the postsynaptic events in the cerebellar cortex is not known (Xu-Friedman and Regehr, 2003).

The number of the granule cells is approximately four millions in one $\mathrm{mm}^{3}$ cerebellar cortex tissues (Berends et al., 2004; Kim et al., 2013). One mossy fiber glomerulus contacts at least 50 granule cell dendrites (Jakab and Hámori, 1988). Considering that a single granule cell has 4-5 dendrites and a mossy axon gives at least 20-25 axonal glomeruli, this means several hundreds of granule cells will be activated for every mossy axon (Kim et al., 2013). This is a strong divergence at the first cerebellocortical synapse, which is not seen in other (cerebrocortical, hippocampal and striatal) circuits. On the other hand, the mossy axon terminal contains a large number of synaptic vesicles: the large synaptic vesicle population possibly results in a sustained strong excitation because of the large amount of released glutamate, and also the spill over of glutamate around the glomerulus (Xu-Friedman and Regehr, 2003). This divergence on the level of the first synapse is possibly responsible for the slow increase of the number of the c-fosIR cell 
nuclei in the cerebellar cortex during the 4-AP seizure. The postsynaptic granule cell AMPA receptors display desensitization (Xu-Friedman and Regehr, 2003), which further contributes to the relatively slow dynamics of postsynaptic $c$-fos gene expression. The presence of the NMDA receptors on the granule cell dendrites possibly helps the effectivity of the mossy fiber stimulation and the $c$-fos expression. The different vermal lobules showed very similar activation dynamics: the number of the c-fosIR cell nuclei increased stepwise from $1.5 \mathrm{~h}$ to $3 \mathrm{~h}$. The anterior lobe receives mainly spinocerebellar, trigeminocerebellar and cuneocerebellar afferents (Voogd, 2004). Lobule V receives pontocerebellar- and lobules IX-X receive vestibulocerebellar mossy fiber afferents (Voogd, 2004). These afferents will be stimulated equally by the 4-AP injections: as a result glutamate release will increase continuolusly. The posterior lobe receives pontocerebellar and reticulocerebellar mossy fibers; lobules IX and X receive afferents from the vestibular nuclei, lobule VIII is also innervated by cuneocerebellar mossy fibers (Voogd, 2004). These mossy afferents are stimulated by 4-AP in a similar pattern. These 4AP stimulated mossy fiber systems activate the vermal lobules with similar dynamics, resulting in a uniform vermal activation at every time point investigated; as shown by our present investigations

5.3 Effects of the glutamate receptor antagonists on the seizure symptoms and the c-fos expression in the cerebellar cortex

The pontine nuclei provide the largest part of the mossy fiber input to the cerebellar cortex (Vejas, 1985). The glutamatergic pontocerebellar system terminates in form of mossy fibers in the granular layer of the cerebellar cortex stimulating mainly granule cells and Golgi cells (Castejon and Castejon, 2000). Whilst these mossy fibers use mainly glutamate, granule cells possess ample NMDA- and AMPA receptors on their dendrites (Geurts et al., 2003; Koutsouraki et al., 2013). Both NMDA- and AMPA receptors are able to induce the expression of transcription factors through the strong postsynaptic $\mathrm{Ca}^{++}$influx (Michael and Rogawsky, 2013; Rothan et al., 2017). We think that 4-AP in the cerebellum induced 
c-fos expression partly through the increased release of glutamate from the mossy fibers, and as a consequence the increase of $\mathrm{Ca}^{++}$influx into the postsynaptic cells (Szakács et al., 2003). Cerebellar granule cells possess $\mathrm{Ca}^{++}$permeable AMPA receptors (Savidge and Bristow 1997) which means, that $\mathrm{Ca}^{++}$entry will be facilitated at postsynaptic structures surrounding the mossy fibers. This ionotropic glutamate transmission mechanism explains our observations on the significant increase of c-fos protein in the cerebellar cortex in 4-AP seizures (Tóth et al., 2015; Tóth et al., 2018; Krisztin-Péva et al., 2019). We think that our presented experiments also support this postulated mechnism: the pharmacological antagonism of the NMDA- and AMPA receptors decreased the number of the c-fosIR cells significantly. It has been proven that pretreatment with AMPA- and NMDA receptor antagonists decreased significantly the number of c-fosIR cell nuclei in the cerebral neocortex and hippocampus (Szakács et al., 2002; Weiczner et al., 2008). We conclude that these drugs can decrease the cerebellar activity through postsynaptic mechanisms, acting at the dendrites of the granule cells and decreasing their firing upon the mossy fiber activity (Delvendahl and Hallermann, 2016). The pharmacologically inhibited firing of the granule cells is reflected by the decrease of the postsynaptic c-fos protein expression in the granular layer of the cerebellar cortex (Tóth et al., 2018).

The GYKI-52466 is a selective, non-competitive AMPA receptor antagonist (Donevan and Rogawski, 1993). It has been reported that the density of the AMPA receptors is very high in the cerebellar cortex (Hampson et al., 1992). The granule cells and the Golgi cells possess AMPA receptors (Hack et al., 1995). The AMPA receptors of the granule cells are relatively resistant to desensitization, and support the high-frequency synaptic transmission in the mossy fiber glomerulus (Dalvendahl and Hallermann, 2016). The GluR1 subunit is also expressed by Bergmann glia cells (Baude et al., 1994). Glial (astrocytic and Bergmann-glial) AMPA receptors play important role in glutamatergic transmission of the cerebellar cortex (Cervetto et al., 2015). As to the pharmacological properties of cerebellar glial AMPA receptors, it was proven, that GYKI-52466 was an effective antagonist in Bergmann glia-mediated aspartate release (Cervetto et al., 2015).

The MK-801 is a high-affinity NMDA (N-methyl-D-aspartate) receptor antagonist (Chapman 1998). Amantadine is a low affinity open-channel blocker of NMDA glutamate receptors (Parsons et al., 1998). These drugs have potential neuroprotection effect as well (Danysz et al., 1997). The NMDA receptor has important role in memory, motor coordination and neurodegeneration as well. Immunohistochemical studies revealed the distribution of the NMDA receptor subtypes (NR1, NR2A-NR2D) in the cerebellar cortex 
(Thompson et al., 2000). Golgi cells express NR1, NR2B, granule cells are immunopositive for NR1, NR2A, NR2C, NR2D. Purkinje cells display NR1, NR2B, NR2C/D immunoreactivity (Thompson et al., 2000). The NMDA receptors obviously play an important role in the fast synaptic transmission of the cerebellar mossy fiber synapses (Delvendahl and Hallermann, 2016). There are literature data, that presynaptic NMDA receptors containing NR2D subunit regulate GABA release in the cerebellar cortex (Dubois et al., 2016). The antagonists acting at these NMDA receptors (e.g.: ifenprodil) may have inhibitory effect on GABA release, further complicating the pharmacological effects of glutamate in the cerebellar cortex (Dubois et al., 2016).

5.4 The role of the mossy fibers in seizure induced c-fos expression of the cerebellar granule cells

The role of mossy fiber afferents in $c$-fos gene activation of the granule cells was clearly supported by our experiments: deafferentation through the transection of the MCP caused an overall, significant decrease of detectable c-fos protein in the cerebellar cortex. The unilateral cutting of the MCP decreased the seizure induced c-fos protein expression not only on the operated side but also in the vermis and in the contralateral, non-operated side, as detected by the Western blots. This is in accord with the characteristic branching pattern of the mossy axons entering through the MCP: the axons give branches, which innervate the ipsilateral cortex, the vermis, then pass to the contralateral cerebellar cortex through the cerebellar commissure (Ruigrook, 2004; Voogd, 2004). The distribution of the ipsilateral and contralateral mossy collaterals was investigated in the paramedian lobule, pyramis and uvula: 69\%:31\%, 71\%:29\% and 65\%:35\% distributions were described (Zgucznski et al., 2010). It has been also described that cerebellar atrophy occurred in a group of patients with chronic epilepsy with significant reductions in Purkinje cell linear densities (Honavar and Meldrum, 2002). At the same time cerebellar cortical radial gliosis was detected (Thom, 2004). Our results clearly proved that following the destruction of the MCP, the c-fos immunoreactivity of the granular layer decreased significantly in both cerebellar hemispheres. This strengthened the hypothesis that the (perhaps synchronised) excitation at the synapses of mossy fibers activated large populations of cerebellar granule cells. This large scale activation involved the entire posterior lobe (the main target of the pontocerebellar axons - Voogd, 2004). Due to this synchronized afferent activation, the cerebellar cortex was unable to participate in movement regulation - instead, the strong 
granule cell excitation generated a failure of the cerebellar output mechanisms: thereby increasing the breakdown of motor regulation in epilepsy (D'Angelo and De Zeeuw, 2008). The failure of the regulation of muscle tone contributes to the symptoms of the motor convulsions: therefore we detect the increased extensor tone at the height of the generalized convulsions (tonic phase). We hypothesize, that the strong mossy fiber activation is partly due to the local effect of 4-AP: it is also caused by the strong excitation of the corticopontine tracts (including the motor tracts running in the basis of the pons Ruigrok, 2004). The forebrain seizure is generated by neocortical-entorhinal-hippocampal circuits (Kopniczky et al., 2005). This forebrain activity will spread to the pontine nuclei and the reticulotegmental nucleus (Voogd, 2004). The mossy fibers originating from these pontine structures will be activated and cause a long-lasting and large-scale excitation of the cerebellar cortex. This excitation is reflected by the significant increase of the number of c-fosIR cell nuclei. If the cerebellar activation is long-lasting and recurrent (as it can be in chronic epilepsies), it might be responsible for the cerebellar atrophy seen regularly in autopsy of patients having had chronic epilepsy (Ney et al., 1994). However, as seen from our immunohistochemical and Western blotting results, the activating power of the mossy axon is larger on the side of the corresponding MCP. The Western blots showed a significant decrease on the contralateral (non-operated) hemisphere, and another, larger decrease on the operated side. Although there were no significant differences between the two hemispheres, the ratio of the decrease in the two hemispheres was very similar to the distribution rates of the mossy fiber collaterals (Zgucznski et al., 2010).

\section{CONCLUSIONS}

1. Generalized tonic-clonic seizures precipitated by the potassium channel blocker 4aminopyridine, caused a long-lasting c-fos protein expression in the granular layer of the cerebellar cortex, indicating long lasting neuronal hyperactivity.

2. The vermal lobules (I-X) displayed a uniform activation pattern pointing to the concerted activation of cerebellar afferents during the seizure. 
3. Transection of the middle cerebellar peduncle on the left side abolished most of the c-fos immunoreactivity, proving the pivotal role of the mossy fiber afferents in cerebellar seizures.

4. The importance of the NMDA and AMPA-type glutamate receptors in the precipitation and maintenance of cerebellar seizures have been proven by the significant decrease of seizure-induced c-fos immunoreactivity of the granular layer following the administration of receptor antagonists.

\section{AKNOWLEDGEMENTS}

I would like to express my gratitude to András Mihály, (Professor of the Department of Anatomy, Histology and Embryology, Faculty of Medicine, University of Szeged) for the opportunity to work and support my research work.

I am indebted to my co-authorBeáta Krisztin-Péva (Department of Anatomy, Histology and Embryology, Faculty of Medicine, University of Szeged) for her professional help the statistical analyses.

I wish to express my thanks to Gergely Molnár (Department of Anatomy, Histology and Embryology, Faculty of Medicine, University of Szeged) for valuable help and work on Western blotting. 
My thanks are due to Zsolt Kopniczky (Institute of Surgical Research, Faculty of Medicine, University of Szeged) for working out the neurosurgical procedure.

I wish to thank to Mónika Kara, Gabriella Pap, Andrea Kobolák and Marietta Morvai for technical help.

Last but not least I wish to express my thanks for my wife Dr. Nóra Palotai.

During the preparation of the first manuscript Dr. Zoltán Tóth (first author) was financially supported byTÁMOP 4.2.4.A/2-11-1-2012-0001 (National Excellence Program).

During the preparation of the second manuscript (Acta Histochemica, 2018) our work was supported by GINOP 2.3.2-2015-16-00034.

The photographs of the convulsing rat (Fig. 2) was kindly supplied by Prof. A. Mihaly. 


\section{REFERENCES}

1. Arai, A.C., 2001. GYKI 52466 has positive modulatory effects on AMPA receptors. Brain. Res. 892,396-400.

2. Azizi SA, Mihailoff GA, Burne RA, Woodward DJ. The pontocerebellar system in the rat: an HRP study. I. Posterior vermis. J Comp Neurol 1981; 197: 543-58.

3. Baude, A, Nusser, Z, Latawiec, D, McIlhinney, R.A.J., Somogyi, P., 1994. Synaptic and nonsynaptic localization of the GluR1 subunit of the AMPA-type excitatory amino acid receptor in the rat cerebellum. J. Neurosci. 14,2830-2843.

4. Berends M, Maex R, De Schutter E. A detailed three-dimensional model of the cerebellar granular layer. Neurocomputing 2004; 58-60: 587-92.

5. Boop S, Wheless J, Van Poppel K, McGregor A, Boop FA. Cerebellar seizures. Report of 2 cases. J Neurosurg Pediatrics 2013; 12: 288-92.

6. Botez MI, Ezzedine A, Vezina JL. Cerebellar atrophy in epileptic patients. Brain Res. 1984;304:166-169.

7. Braitman, D.J., Sparenborg, S., 1989. Mk-801 protects against seizures induced by the cholinesterase inhibitor soman. Brain. Res. Bull. 23,145-148.

8. Brodal P, Bjaalie JG. Salient anatomic features of the cortico-ponto-cerebellar pathway.

Brain Res 1979;114:227 - 49.

9. Castejon, O.J, Castejon, H.V., 2000. Correlative microscopy of cerebellar Golgi cells. Biocellular 24,13-30.

10. Chapman, A.G., 1998. Glutamate receptors in epilepsy. Prog. Brain Res. 116,371383.

11. Crooks R, Mitchell T, Thom M. Patterns of cerebellar atrophy in patients with chronic epilepsy: a quantitative neuropathological study.

Epilepsy Research 2000;41:63-73.

12. Cull-Candy S, Brickley S, Farrant M. NMDA receptor subunits: diversity, development and disease. Curr Op Neurobiol 2001; 11: 327-35. 
13. D'Angelo E, De Zeeuw CI. Timing and plasticity in the cerebellum: focus on the granular layer. Trends Neurosci 2008; 32: 30-40.

14. D'Angelo E. The organization of plasticity in the cerebellar cortex: from synapses to control. Prog. Brain. Res 2014;210:31-58

15. Dam M, Wolf P, Janz D, Dreifus FE. Neuropathology of the cerebellum.

16. Danysz, W, Parsons, C.G., Kornhuber, J, Schmidt, W.J., Quack, G., 1997. Aminoadamantanes as NMDA receptor antagonists and anti-parkinsonian agents. Neurosci. Biobehav. Rev. 21,455-468.

17. De Marco FA, Ghizoni E, Kobayashi E, Min L, Cendes F. Cerebellar volume and long-term use of phenytoin. Seizure 2003;12:312-315.

Epilepsy Res 2000;41:63-73.

18. Gass P, Herdegen T, Bravos R, Kiessling M. Induction of immediate-early gene encoded protein sin the rat hippocampus after bicuculline-induced seizures: differential expression of KROX-24, Fos and Jun proteins. Neuroscience 1992; 48: 315-24.

19. Geurts FJ, De Schutter E, Dieudonné S. Unravelling the cerebellar cortex: cytology and cellular physiology of large-sized interneurons in the granular layer. The Cerebellum 2003; 2: 290-9.

20. Glaum, S.R., Holzwarth, J.A., Miller, R.J., 1990. Glutamate receptors activate $\mathrm{Ca} 2+$ mobilization and $\mathrm{Ca} 2+$ influx into astrocytes. Proc Natl Acad Sci USA 87,3454-3458.

21. Hampson, D.R., Huang, X.P., Oberdorfer, M.D., Goh, J.W, Auyeung, A., Wenthold, R.J., 1992. Localization of AMPA receptors in the hippocampus and cerebellum of the rat using an anti-receptor monoclonal antibody. Neurosci. 50,1122.

22. Hansson, E., Rönback, L., 1995. Astrocytes in glutamate neurotransmission. FASEB J. 9,343-350.

23. Herdegen T, Leah JD. Inducible and constitutive transcription factors in the mammalian nervous system: control of gene expression by Jun, Fos and Krox, and CREB/ATF proteins. Brain Res Rev 1998; 28: 370-490.

24. Hirano T. Long-term depression and other synaptic plasticity in the cerebellum. Proc Jpn Acad Ser B 2013; 89: 183-95.

25. Honavar M, Meldrum BS. Epilepsy. In: Graham DI, Lantos P, editors. Greenfield's 
Neuropathology. Arnold, London 2002, p. 899-941.

26. Hösli, E., Hösli, L., 1990. Receptors for neurotransmitters on astrocytes in the mammalian central nervous system. Prog Neurobiol 40,477-506.

27. Ito M. The Cerebellum and Neural Control.

J Neural Transm Suppl. 1984; 43,91-104.

28. Jakab RL, Hámori J. Quantitative morphology and synaptology of cerebellar glomeruli in the rat. Anat Embryol 1988; 179: 81-88.

29. Kim H-W, Kim N, Kim KW, Rhyu IJ. Three-dimensional imaging of cerebellar mossy fiber rosettes by ion-abrasion scanning electron microscopy. Microsc Microanal 2013; 19: 172-177.

30. Kopniczky Zs, Dobó E, Borbély S, Világi I, Détári L, Krisztin-Péva B, Bagosi A, Molnár E, Mihály A. Lateral entorhinal cortex lesions rearrange afferents, glutamate receptors, increase seizure latency and suppress seizure-induced c-fos expression in the hippocampus of adult rat. J Neurochem 2005; 95: 111-24.

31. Kornhuber, J.1., Weller, M., Schoppmeyer, K., Riederer, P., 1994. Amantadine and memantine are NMDA receptor antagonists with neuroprotective properties.J Neural Transm Suppl. 43,91-104.

32. Kostopoulos GK. Involvement of the thalamocortical system in epileptic loss of consciousness. Epilepsia. 2001;42 Suppl 3:13-9. Review.

33. Koutsouraki, E.,S., Anastasiades, J.J., 2013. Baloyannis SJ. An immunohistochemical study of n-methyl-D-aspartate receptor sin human cerebellumand hippocampus. Am J Med Sci Med 1,28-30.

34. Kovács A, Mihály A, Komáromi Á, Gyengési E, Szente M, Weiczner R, KrisztinPéva B, Szabó G, Telegdy G. Seizure, neurotransmitter release and gene expression are closely related in the striatum of 4-aminopyridine-treated rats. Epilepsy Res 2003; 55: 117-29.

35. Krisztin-Péva B, Mihály A, Tóth Z. Differential expression of the c-fos protein and synaptophysin in zebrin II positive and zebrin II negative cerebellar cortical areas in 4-aminopyridine seizures Acta Neurobiol Exp 2019, 79: 239-251 
36. Labiner DM, Butler LS, Cao Z, Hosford DA, Shin C, McNamara JO. Induction of c-fosmRNA by kindled seizures: complex relationship with neuronal burst firing. $\mathrm{J}$ Neurosci1993; 13: 744-51.

37. Lemeignan M, Millart H, Lamiable D, Molgo J, Lechat P. Evaluation of 4aminopyridine and 3,4-diaminopyridine penetrability into cerebrospinal fluid in anesthetised rats.

38. Maria Thom. Hippocampal sclerosis in epilepsy: a neuropathology review. Neuropathology and Applied Neurobiology (2014), 40, 520-543

39. Meeldrum, B., Garthwaite, J., 1990. Excitatory amino acid neurotoxicitiy and neurodegenerative desease, Trends Pharmacol Sci. 11,379-387.

40. Middleton FA, Strick PL. Cerebellar output: motor and cognitive channels. Trends Cogn Sci 1988;2:348-54.

41. Mihály A, Borbély S, Világi I, Détári L, Weiczner R, Zádor Z, Krisztin-Péva B, Bagosi A, Kopniczky Zs, Zádor E. Neocortical c-fos mRNA transcription in repeated, brief, acute seizures: is c-fos a coincidence detector? Internat J Mol Med 2005; 15: 481-6.

42. Mihály A, Szakács R, Bohata C, Dobó E, Krisztin-Péva B. Time-dependent distribution and neuronal localization of fos protein in the rat hippocampus following 4-aminopyridine seizures. Epilepsy Res 2001; 44: 97-108.

43. Mihály A, Szente M, Dubravcsik Z, Boda B, Király E, Nagy T, Domonkos Á. Parvalbumin- and calbindin-containing neurons express c-fos protein in primary and secondary (mirror) epileptic foci of the rat neocortex. Brain Res 1997; 761: $135-45$.

44. Mohamed IS, Otsudo H, Ferrari P, Ochi A, Carter Snead O, Cheyne D. Neuromagnetic cerebellar activation during seizures arising from the motor cortex. Epilepsy Res 2011; 96: 283-7.

45. NeyGC, LantosG,BarrWB,SchaulN.Cerebellaratrophyinpatients withlongtermphenytoin exposure and epilepsy.Arch. Neurol. 1994;51:767-71.

46. Palesi F, Tournier J-D,Calamante F , Muhlert N, Castellazzi G, Chard D, D'Angelo D, Claudia A. M. Wheeler-Kingshott. Contralateral cerebello-thalamocortical pathways with prominent involvement of associative areas in humans in vivo

Brain Struct Funct (2015) 220:3369-3384 
47. Parsons, C.G., Danysz, W., Quack, G., 1998. Memantine is a clinically well tolerated N-methyl-d-aspartate (NMDA) receptor antagonist. Neuropharmacology $38,735-767$.

48. Pastor J, Sola RG, Ortega GJ. Influence of paroxysmal activity on background synchronization in epileptic recordings. J Neurosci Meth. 2014;223:69-73. doi: 10.1016/j.jneumeth.2013.11.027.

49. Pérez-Kapote, K., Serratosa, J., Solá, C., 2004. Glial activation modules glutamate neurotoxicity in cerebellar grnanule cultures. Glia 45(3),258-268.

50. Rogawski, M.A., 3013. AMPA Receptors as a Molecular Target in Epilepsy Therapy Acta Neurol Scand Suppl. 197, 9-18.

51. Ruigrok TJH. Precerebellar nuclei and red nucleus. In: Paxinos G, editor. The Rat Nervous System. Elsevier; 2004. p. 167-204.

52. Santarnecchi E, Vatti G, Marino D, Polizzotto N, Cerase A, Rocchi R, Rossi A. Cerebro-cerebellar functional connectivity profile of an epilepsy patient with periventricular nodular heterotopia. Epilepsy Res 2012; 101: 280-3.

53. Schahmann JD, Sherman JC. The cerebellar cognitive affective syndrome. Brain 1998; 121: 561-569.

54. Spielmeyer W. The anatomic substratum of the convulsive state.

55. Suárez, I., Bodega, G., Fernández, B., 1997. Modulation of AMPA receptor subunits GluR1 and GluR2/3 in the rat cerebellum in an experimental hepatic encephalopathy model Brain Res. 778,346-353.

56. Szakács, R., Weiczner, R., Mihály, A., Krisztin-Péva, B., Zádor, Z., Zádor, E., 2003. Non-competitive NMDA receptorantagonists moderate seizure-induced c-fos protein expression in the rat cerebral cortex. Brain Res Bull. 59,485-93.

57. Thompson, C.L., Drewery, D.L., Atkins, H.D., Stephenson, F.A., Chazot, P.L., 2000. Immunohistochemical localization of N-methyl-d-aspartate receptor NR1, NR2A, NR2B and NR2C/D subunits in the adult mammalian cerebellum. Neuroscience Letters. 283,85-88.

58. Tokunaga A, Sandri C, Akert K. Ultrastructural effects of 4-aminopyridine on the presynaptic membrane in the rat spinal cord. Brain Res 1979;163:1-8.

59. Tóth, Z., Molnár, G., Mihály, A., Krisztin-Péva, B., Morvai, M., Kopniczky, Z., Immunohistochemistry of cerebellar seizures: Mossy fiber afferents play an important role in seizure spread and initiation in the rat. Acta Histochemica. $2015 ; 117,47-55$. 
60. Zoltán Tóth, András Mihály, Adrienne Mátyás, Beáta Krisztin-Péva. Noncompetitive antagonists of NMDA and AMPA receptors decrease seizure-induced c-fos protein expression in the cerebellum and protect against seizure symptoms in adult rats. Acta Histochemica 2018;120:236-241

61. Vejas, P., 1885. Experimentelle Beitrage zur Kenntnis der Verbind-ungsbahnen des Kleinhirns und das Verlauf der Fun, Gracilis und Cuneatus. Arch. Psychiatris. $16,200-214$.

62. Versteeg GHG, Heemskerk FMJ, Spieremburg HA, Degraan PNE, Schrama LH. 4Aminopyridine differentially affects the spontaneus release of radiolabelled transmitters from rat hippocampal slices.

63. Voogd J. Cerebellum. In: Paxinos G, editor. The Rat Nervous System. Elsevier; 2004. p.205-42.

64. Weiczner R, Krisztin-Péva B, Mihály A. Blockade of AMPA receptors attenuates 4-aminopyridine seizures, decreases the activation of inhibitory neurons but is ineffective against seizure-related astrocytic swelling. Epilepsy Res 2008; 78: 22 32.

65. Wong, E. H. F., Kemp, J.A., Priestly, T., Knight, A.R., Woodruff, G.N., Iversen, L.L., 1986. The anticonvulsant MK-801 is a potent N-methyl-D-aspartate antagonist. Proc. Natl. Acad. Sci. 83,7104-7108.

66. Xu-Friedman, Regehr WG. Ultrastructural contributions to desensitization at cerebellar mossy fiber to granule cell synapses. J Neurosci 2003; 23: 2182-92.

67. Zguczynski L, Bukowska D, Mierzejewska-Krzyzowska B. Organization of thepontocerebellar projection to the paramedian lobule and caudal vermis: a retrogradefluorescent tracer study in the rabbit. Cells Tissues Organs 2010; 192: 395-408. 
Paper I. 
Paper II. 